OPEN ACCESS

Edited by:

Marcelo Anibal Fernandez-Vina,

University of Texas MD Anderson

Cancer Center, United States

Reviewed by:

Lloyd Joseph Andrew D'Orsogna,

Fiona Stanley Hospital, Australia

Bjarne Kuno Møller,

Aarhus University Hospital, Denmark

*Correspondence:

Katharina Fleischhauer

katharina.fleischhauer@uk-essen.de

Specialty section:

This article was submitted to Alloimmunity and Transplantation,

a section of the journal

Frontiers in Immunology

Received: 06 December 2017

Accepted: 31 January 2018

Published: 19 February 2018

Citation:

Arrieta-Bolaños E, Crivello $P$,

Metzing M, Meurer T, Ahci M,

Rytlewski J, Vignali M, Yusko E,

van Balen $P$, Horn $P A$,

Falkenburg JHF and Fleischhauer $K$ (2018) Alloreactive T Cell Receptor

Diversity against Structurally Similar

or Dissimilar HLA-DP Antigens

Assessed by Deep Sequencing.

Front. Immunol. 9:280.

doi: 10.3389/fimmu.2018.00280

\section{Alloreactive T Cell Receptor Diversity against Structurally Similar or Dissimilar HLA-DP Antigens Assessed by Deep Sequencing}

\author{
Esteban Arrieta-Bolaños ${ }^{1}$, Pietro Crivello', Maximilian Metzing', Thuja Meurer', \\ Müberra Ahci', Julie Rytlewski ${ }^{2}$, Marissa Vignali ${ }^{2}$, Erik Yusko' ${ }^{2}$, Peter van Balen ${ }^{3}$, \\ Peter A. Horn', J. H. Frederik Falkenburg ${ }^{3}$ and Katharina Fleischhauer ${ }^{1,5 *}$
}

${ }^{1}$ Institute for Experimental Cellular Therapy, University Hospital Essen, Essen, Germany, ${ }^{2}$ Adaptive Biotechnologies, Seattle, WA, United States, ${ }^{3}$ Department of Hematology, Leiden University Medical Center, Leiden, Netherlands, ${ }^{4}$ Institute for Transfusion Medicine, University Hospital Essen, Essen, Germany, ${ }^{5}$ German Cancer Consortium (DKTK), Heidelberg, Germany

T cell alloreactivity is mediated by a self-human leukocyte antigen (HLA)-restricted T cell receptor (TCR) repertoire able to recognize both structurally similar and dissimilar allogeneic HLA molecules (i.e., differing by a single or several amino acids in their peptidebinding groove). We hypothesized that thymic selection on self-HLA molecules could have an indirect impact on the size and diversity of the alloreactive response. To test this possibility, we used TCR V $\beta$ immunophenotyping and immunosequencing technology in a model of alloreactivity between self-HLA selected T cells and allogeneic HLA-DPB1 (DPB1) differing from self-DPB1*04:02 by a single (DPB1*02:01) or several (DPB1*09:01) amino acids in the peptide-binding groove. CD4+ $T$ cells from three different selfDPB $1{ }^{*} 04: 01,{ }^{*} 04: 02$ individuals were stimulated with HeLa cells stably transduced with the relevant peptide processing machinery, co-stimulatory molecules, and HLA-DP. Flow cytometric quantification of the DPB1-specific T cell response measured as upregulation of the activation marker CD137 revealed significantly lower levels of alloreactivity against DPB $1{ }^{*} 02: 01$ compared with DPB1 ${ }^{*} 09: 01$ (mean CD4+CD137+ frequency $35.2 \pm 9.9$ vs. $61.5 \pm 7.7 \%$, respectively, $p<0.0001$ ). These quantitative differences were, however, not reflected by differences in the breadth of the alloreactive response at the $\vee \beta$ level, with both alloantigens eliciting specific responses from all TCR-V $\beta$ specificities tested by flow cytometry, albeit with higher levels of reactivity from most $\mathrm{V} \beta$ specificities against DPB1*09:01. In line with these observations, TCRB-CDR3 immunosequencing showed no significant differences in mean clonality of sorted CD137+CD4+ cells alloreactive against DPB1 ${ }^{\star} 02: 01$ or DPB1*09:01 [0.39 (0.36-0.45) and $0.39(0.30-0.46)$, respectively], or in the cumulative frequencies of the 10 most frequent responding clones (55-67 and 58-62\%, respectively). Most of the clones alloreactive against DPB1*02:01 (68.3\%) or DPB1*09:01 (75.3\%) were characterized by low-abundance (i.e., they were not appreciable among the pre-culture T cells). Interestingly, however, their cumulative frequency was lower against DPB1 ${ }^{\star} 02: 01$ compared with DPB1*09:01 (mean cumulative frequency 35.3 vs. $50.6 \%$, respectively). Our data show that, despite lower levels 
of alloreactivity, a similar clonal diversity can be elicited by structurally similar compared with structurally dissimilar HLA-DPB1 alloantigens and demonstrate the power of TCRB immunosequencing in unraveling subtle qualitative changes not appreciable by conventional methods.

Keywords: T-cell alloreactivity, T-cell receptor repertoire, next-generation sequencing, human leukocyte antigenDPB1, permissive mismatches

\section{INTRODUCTION}

T cell alloreactivity against the human leukocyte antigen (HLA) system is a major barrier to successful transplantation of organs and stem cells. Alloreactivity is mediated by a $\mathrm{T}$ cell repertoire shaped by thymic selection to be self-HLA restricted, but at the same time capable of recognizing non-self-HLA. The fact that a large proportion of $\mathrm{T}$ cells is capable of recognizing previously unseen alloantigens $(1,2)$ remains an enigma of $\mathrm{T}$ cell biology. $\mathrm{T}$ cell alloreactivity involves a complex interplay between the polymorphic foreign HLA molecule, the peptides being presented by it, and the self T cell receptor (TCR) (3). Although the relative contribution of each of these components to alloreactivity is not completely understood, it is conceivable that amino acid changes in the peptide-binding region of a given HLA molecule may ensue changes in the biochemical and/or structural properties of the binding pockets, thereby impacting the amino acid sequence and/or conformation of peptides able to be presented by it. Alternatively, these amino acid changes could directly affect the interaction between the HLA molecule and the TCR (4). Whether the number of amino acid differences in the peptidebinding region of the HLA molecule results in higher or lower levels of alloreactivity and whether this arises from a broader or narrower alloreactive $\mathrm{T}$ cell response is a matter of debate.

Of note, it has been shown that even a single amino acid difference in the peptide-binding region of HLA class I molecules HLA-B ${ }^{\star} 44: 02$ and $\mathrm{B}^{\star} 44: 03$ can elicit a $\mathrm{T}$ cell response sufficient to cause allograft rejection (5) or graft-vs.-host disease (GvHD) (6) after hematopoietic stem cell transplantation (HSCT). In addition, in vitro measurements of the patient-donor immune response before HSCT, mainly based on direct recognition of mismatched HLA class I antigens, have suggested that the number of amino acid differences is inversely correlated with the amount of direct $\mathrm{T}$ cell allorecognition (7), although this concept was not supported by clinical associations with HSCT outcome (8). Our understanding, control, and capacity to harness alloreactivity in the transplantation setting are still incomplete.

HLA-DPB1 (DPB1) represents an attractive model for the study of alloreactive responses to HLA molecules. Previous work by us $(9)$ and others $(10,11)$ has shown differential alloreactivity to allogeneic DPB1 according to a functional classification of its different allelic variants (12). Amino acid changes resulting in structural and functional dissimilarities between DPB1 alleles were shown to have a strong median impact on alloreactive responses to these molecules (13), allowing for the classification of DPB1 mismatches as permissive (structural similarity and low alloreactivity) or non-permissive (structural dissimilarity and higher alloreactivity) in the clinical setting $(14,15)$. Importantly, the classification of a mismatch as permissive or non-permissive depends on the self-HLA background of the responder, following the concepts of thymic $\mathrm{T}$ cell education (16). However, direct evidence for the hypothesis that thymic selection on self-alleles has an indirect impact on the size and diversity of the alloreactive response has yet to be obtained. Here, we have sought to fill this gap by characterizing the alloreactive TCR diversity from self-DPB1 ${ }^{\star} 04: 01,{ }^{*} 04: 02$ individuals against alloantigens carrying a single $\left(\mathrm{DPB} 1^{\star} 02: 01\right)$ or multiple (DPB1 $\left.{ }^{\star} 09: 01\right)$ amino acid differences in the peptide-binding groove using a unique system of single-DPB1 allele-expressing cells, and TCR V $\beta$ immunophenotype and deep immunosequencing of the TCRB gene.

\section{MATERIALS AND METHODS}

\section{Subjects and Cells}

Buffy coats from three healthy blood donors were obtained in order to isolate peripheral blood mononuclear cells (PBMC) by Ficoll centrifugation. All blood donors had been typed as self-DPB1 ${ }^{\star} 04: 01,{ }^{\star} 04: 02$ by standard molecular methods and were CMV seronegative. Demographic details of each subject are presented in Table 1. PBMC were then used to isolate untouched $\mathrm{CD} 4+\mathrm{T}$ cells via magnetic beads according to the manufacturer's instructions (Miltenyi Biotec $\mathrm{GmbH}$, Bergisch Gladbach, Germany). Purified CD4+ T cells (average 97.7\%, range: $96.7-98.3 \%$ of live cells, with a CD8+ mean content of $0.02 \%$, range: $0.01-0.04 \%$ ) were used as responders in coculture with stimulating cells as described subsequently. All participants gave informed consent, and this study was approved by the local ethics committee of University Hospital Essen.

\section{Expansion of DPB1-Specific CD4+ Cells}

In order to expand DPB1-specific alloreactive T cells, purified CD4+ cells from each donor were cocultured with HeLa cells expressing single specific HLA-DP molecules as described previously $(17,18)$. In brief, HeLa cells, which normally do not express HLA class II molecules, were retrovirally transduced with specific HLA-DP molecules (DPB1 and the naturally associated DPA1

TABLE 1 | HLA, CMV, and demographic data for the healthy subjects used in this study.

\begin{tabular}{|c|c|c|c|c|}
\hline Subject & DPB1 typing & CMV serostatus & Age (years) & Gender \\
\hline $\mathrm{R} 1$ & ${ }^{\star} 04: 01,{ }^{*} 04: 02$ & Negative & 67 & Male \\
\hline $\mathrm{R} 2$ & ${ }^{\star} 04: 01,{ }^{*} 04: 02$ & Negative & 56 & Male \\
\hline R3 & ${ }^{*} 04: 01,{ }^{*} 04: 02$ & Negative & 21 & Female \\
\hline
\end{tabular}

CMV, cytomegalovirus; HLA, human leukocyte antigen; $R$, responder. 


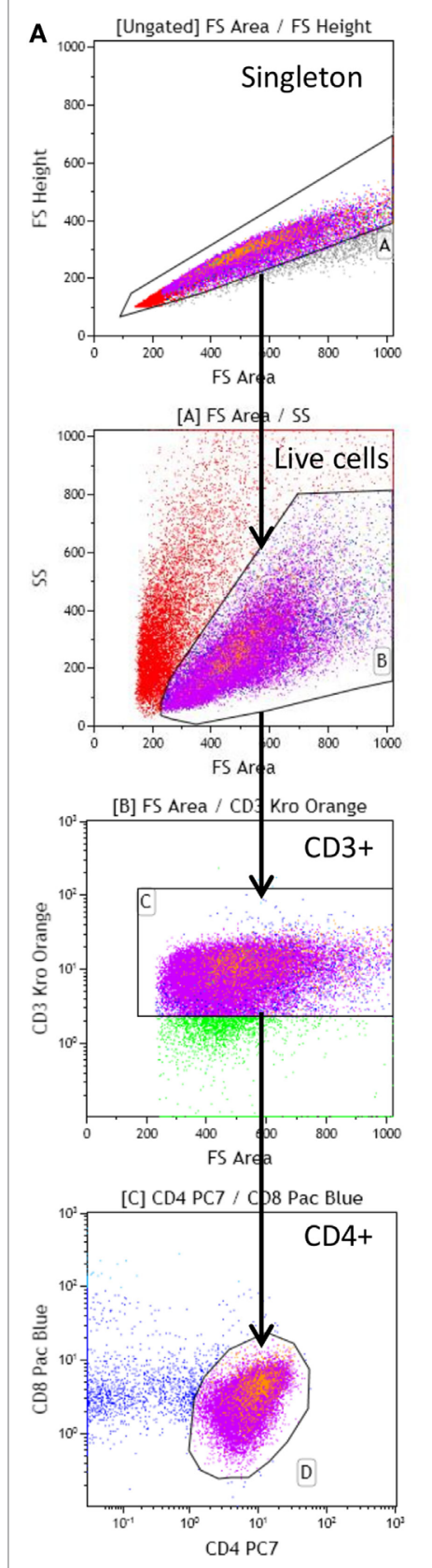

B

DPB1*04:01

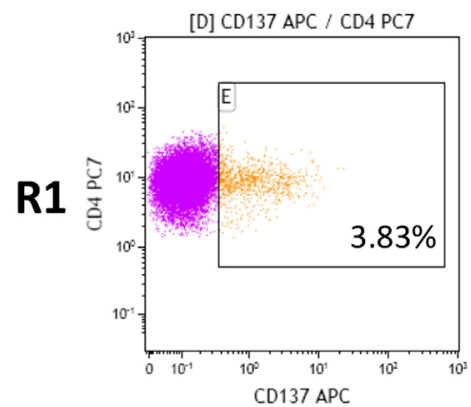

DPB1*02:01

DPB1*09:01
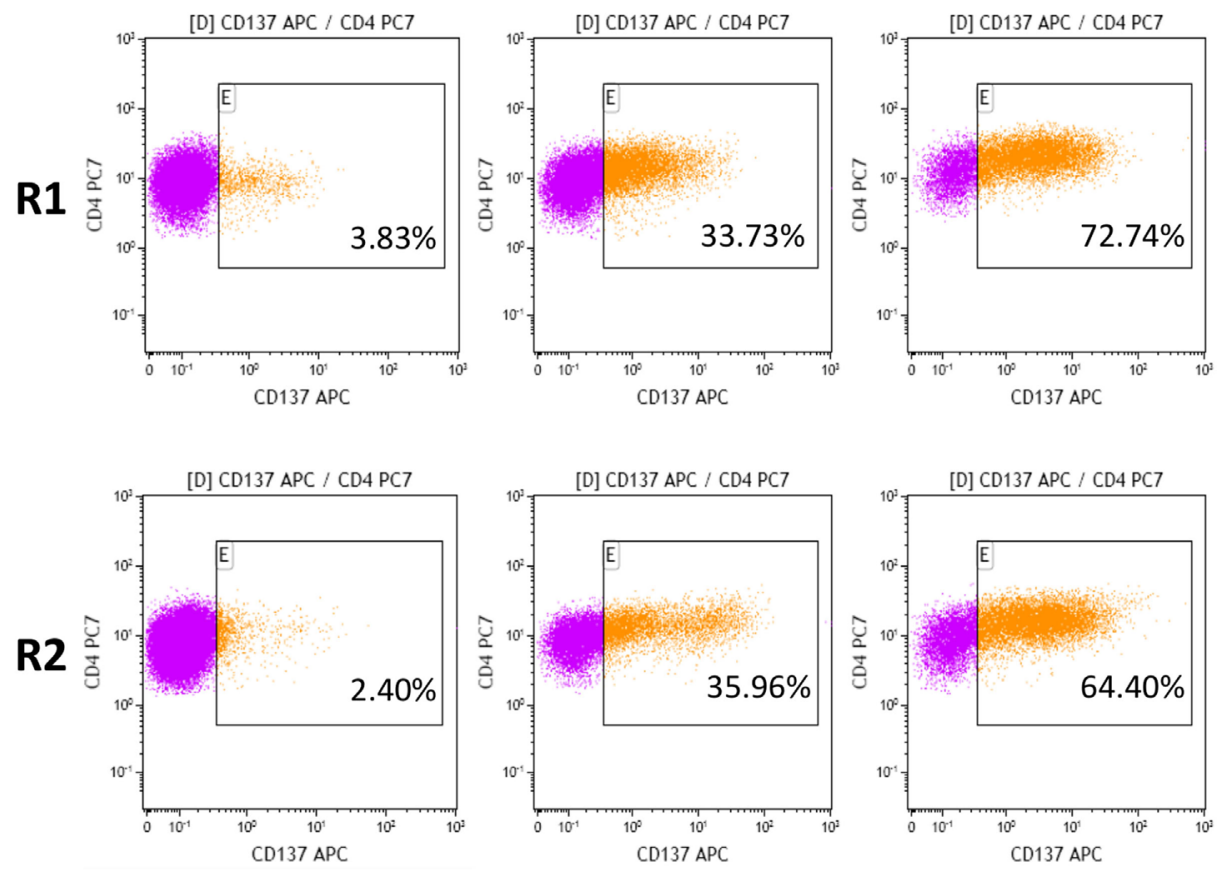

R3
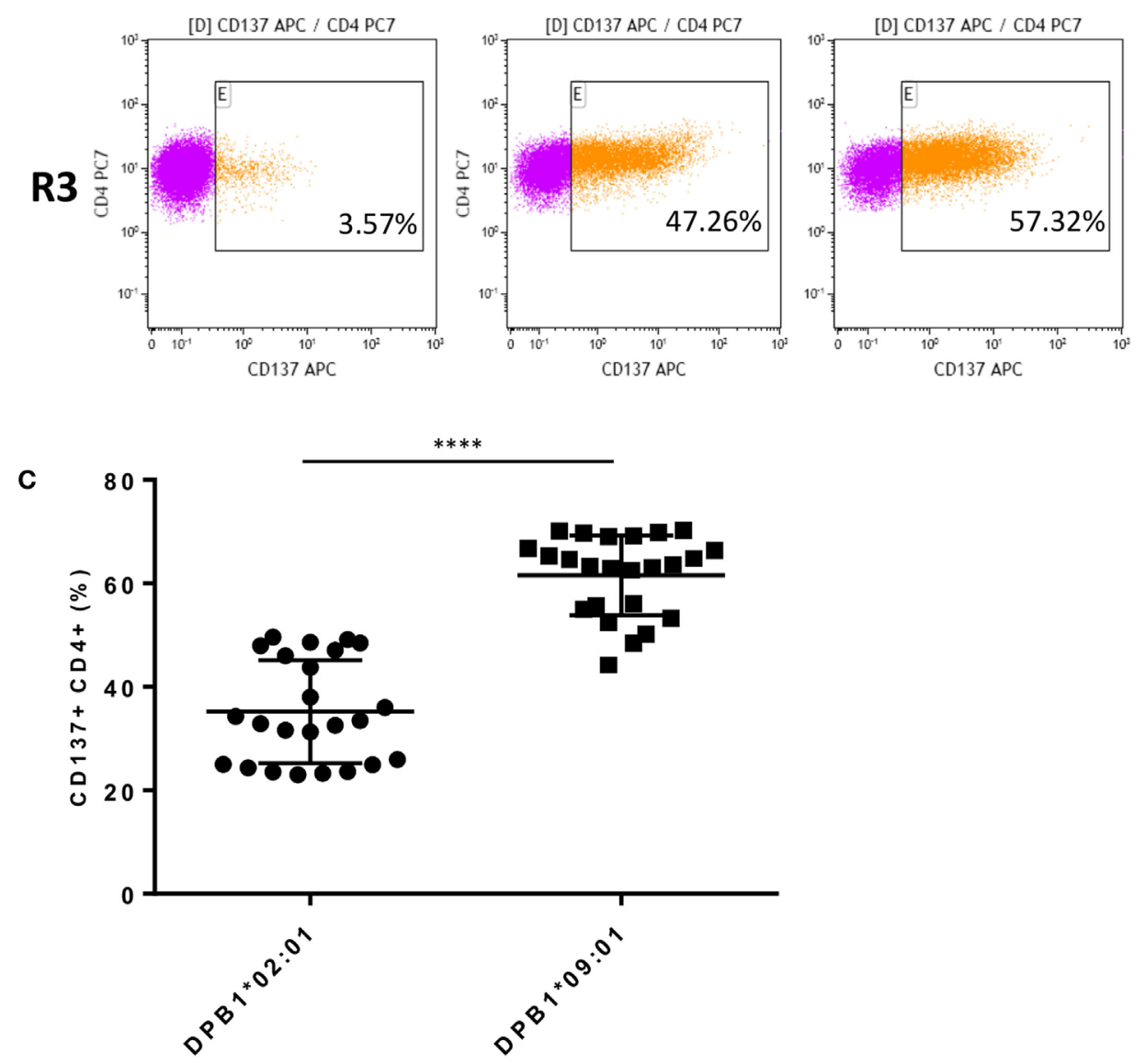

FIGURE 1 | Continued 
FIGURE 1 | Alloresponses from self-DPB1*04:01, ${ }^{\star} 04: 02$ individuals against HLA-DPB1*02:01 and DPB1*09:01 result in stronger responses against the latter. Isolated untouched CD4+ T cells from the three self-DPB1 ${ }^{\star} 04: 01 /{ }^{*} 04: 02$ responders $(\mathrm{R})$ were cocultured with HeLa cells expressing DPB1 ${ }^{\star} 02: 01$ or DPB1 ${ }^{\star} 09: 01$. After 2 weeks, expanded alloreactive T cells were restimulated for $24 \mathrm{~h}$ against HeLa cells expressing the original DPB1 alloantigen or an autologous allele, and the degree of T cell response was quantified as the proportion of CD4+CD137+ cells. (A) Gating strategy: cells are gated on the live cells and CD3+CD4+ cells. (B) Representative responses from each of the subjects. Left panels, background response of alloreactive cells against the autologous allele DPB1*04:01; middle panels, response against allogeneic DPB1*02:01; and right panels, response against allogeneic DPB1*09:01. (C) The specific response against each allele was quantified in parallel repeats $(n=8)$ for each subject after deduction of the background levels of CD137 positivity against HeLa expressing the autologous allele (average 4.11\%). Mean response (and SD) against DPB1*02:01 and DPB1*09:01 was 35.2\% (9.95) and 61.54\% (7.69), respectively ( $p<0.0001)$.

genes) and the necessary machinery for HLA class II antigen presentation (HLA-DM and invariant chain) and co-stimulation (CD80) and used as antigen-presenting cells. Expression of the DP heterodimer was confirmed by flow cytometry (anti-DP clone B7/21; Leinco Technologies, Inc., St. Louis, MO, USA) with comparable levels among different transduced cells (data not shown). Purified CD4+ T cells (typically 1.2 million) were cultured in RPMI (c.c.pro $\mathrm{GmbH}$, Oberdorla) supplemented with L-glutamine $(2 \mathrm{mM})$, penicillin-streptomycin (100 ng/ $\mathrm{mL}$ ), and $10 \%$ human $\mathrm{AB}$ serum at a ratio of $3: 1$ with irradiated (100 Gy) HeLa cells in the presence of $50 \mathrm{U} / \mathrm{mL}$ IL-2 in 24-well plates. Parallel cocultures were set up for each subject using $\mathrm{HeLa}$ expressing $\mathrm{DPB} 1^{\star} 02: 01$ (one peptide-binding groove amino acid difference with $\left.\mathrm{DPB} 1^{\star} 04: 02\right)$ or $\mathrm{DPB} 1^{\star} 09: 01$ (10 peptidebinding groove amino acid differences with $\left.\mathrm{DPB} 1^{\star} 04: 02\right)$. After 15 days, expanded CD4+ T cells were rechallenged for $24 \mathrm{~h}$ with HeLa expressing the allogeneic stimulator DPB1 at the same ratio in order to assess the alloreactive response in terms of CD137+ (i.e., activated) T cells by flow cytometry (19). HeLa cells transduced to express one of the donors' self-HLA DPB1 molecules (i.e., ${ }^{\star} 04: 01$ ) were used to determine background activation levels (average $4.1 \%$ ). After rechallenge, $\mathrm{T}$ cells were stained with fluorescently labeled antibodies against CD3 (clone UCHT1, Beckman Coulter, Marseille, France), CD4 (clone SK3, BD Biosciences, Heidelberg, Germany), CD8 (clone B9.11, Beckman Coulter, Marseille, France), and CD137 (clone 4B4-1, BD Biosciences, Heidelberg, Germany), and the proportion of CD137+CD4+ cells was measured on a Gallios flow cytometer (Beckman Coulter GmbH, Krefeld, Germany). CD137+CD4+ cells were then assessed for their TCR diversity as explained subsequently.

\section{TCR V $\beta$ Immunophenotype}

$\mathrm{T}$ cell receptor diversity of anti-DPB1 T cell cultures was assessed in total and CD137+CD4+ cells at the V $\beta$ level by flow cytometry using the IOTest ${ }^{\circledR}$ Beta Mark TCR V $\beta$ Repertoire kit (Beckman Coulter, Marseille, France). For this, one million cultured CD4+ cells were restimulated with the specific HeLa transduced cells for $24 \mathrm{~h}$. Then, the T cells were harvested and stained with subset markers as indicated earlier and the kit's eight $\mathrm{V} \beta$ antibody cocktails according to manufacturer's instructions. The frequency of each of the targeted $\mathrm{V} \beta$ specificities was recorded in the reactive $(\mathrm{CD} 4+\mathrm{CD} 137+)$ fraction. In addition, the proportion of CD137+ cells (responsiveness) among all CD4+ cells expressing each of the V $\beta$ specificities was quantified. Pre-culture-isolated CD4+ cells from each subject were also analyzed in parallel as baseline control.

\section{TCR Immunosequencing}

Next-generation sequencing-based high-throughput TCR analysis (TCR immunosequencing) was carried out in DPB1 alloreactive T cells. For this, two million cultured CD4+ cells were restimulated with the specific HeLa transduced cells for $24 \mathrm{~h}$, after which the T cells were harvested and sorted for CD137 positivity (average purity 93.2\%) using magnetic bead technology according to manufacturer's instructions (Miltenyi Biotec $\mathrm{GmbH}$, Bergisch Gladbach). Enrichment for DPB1-specific alloreactive T cells was confirmed by interferon- $\gamma$ Elispot assays (data not shown). Genomic DNA from sorted CD137+CD4+ cells and pre-culture-isolated CD4+ samples from each subject as baseline controls was subsequently extracted using a DNeasy Blood \& Tissue Kit (QIAGEN GmbH, Hilden, Germany). DNA from each cultured and pre-culture sample was sequenced to determine TCRB complementarity-determining region 3 (CDR3) rearrangements using the immunoSEQ ${ }^{\circledR}$ Assay from Adaptive Biotechnologies (Seattle, WA, USA) as described previously (20, 21). Briefly, a multiplex PCR system based on forward primers targeting $54 T R B V$ segments and reverse primers targeting 13 TRBJ segments was used to amplify the CDR3 region of the TCRB locus. The PCR products were sequenced on an Illumina HiSeq System, and reads of 87 base pairs covering the CDR3 region were obtained. Sequence data were preprocessed to remove PCR and sequencing errors in the primary sequence. CDR3 regions were defined based on alignments to sequences in the international ImMunoGeneTics information system ${ }^{\circledR}(22)$. All cultured samples were analyzed at survey resolution (targeting 60,000 T cell genomes), while pre-culture samples were analyzed at deep resolution (targeting 200,000 T cell genomes). Average input DNA was $218.4 \mathrm{ng}$ (range 137.9-400) for CD137+CD4+ cells and 1,200 ng for preculture CD4+ cells, respectively. The number of templates (total $\mathrm{T}$ cells) and the number of rearrangements (unique T cells) in each sample were estimated based on synthetic template pools as previously described (21).

\section{Diversity Metrics and Statistical Analyses}

Immunosequencing data generated for each sample were analyzed for their TCR diversity in terms of clonality and richness. Clonality was calculated as 1-Pielou's evenness (23), which is a measure of how uniformly distributed the repertoire is, and it is computed as normalized Shannon's Entropy. Clonality values approaching 0 indicate that every rearrangement is present at nearly identical frequency (i.e., less variation in abundance), whereas values approaching 1 indicate a very skewed distribution of frequencies (i.e., more variation in abundance). 
Richness, a measure of the number of different species in a repertoire was assessed using the Daley-Smith estimate (24), a non-parametric empirical Bayes estimator of repertoire richness based on extrapolation of the rarefaction curve to 10 times the actual sample size. TCR clone sharing between samples was assessed by overlap and differential abundance analyses (25), and repertoire similarity was assessed by Morisita's index, a population overlap metric relating the dispersion of clones in the samples (26). The abundance of individual clones was defined by assessing their presence and frequency in pre-culture and cultured samples, and low abundance clones were defined as those seen in cultured samples but undetected in the pre-culture repertoire. CDR3 immunosequencing data were analyzed using custom bioinformatics tools [ $\mathrm{R}$ version 3.3.2 (27) and RStudio version 1.0.136 (28)] and the immunoSEQ Analyzer ${ }^{\circledR}$ (Adaptive Biotechnologies, Seattle, WA, USA). Alloreactivity levels against $\mathrm{DPB} 1^{\star} 02: 01$ and $\mathrm{DPB} 1^{\star} 09: 01$ and pre-culture sample groups were compared using $t$-tests, and $p$-values $<0.01$ were considered statistically significant. Statistical analyses were performed using Prism (version 6.05, GraphPad Software Inc., La Jolla, CA, USA).

\section{RESULTS}

\section{Alloreactive Response against Similar or Dissimilar DPB1 Alleles}

After coculture with DPB1-transduced HeLa cells, alloreactive $\mathrm{T}$ cells were obtained for all three responders studied against the stimulator alloantigen with either a single $\left(\mathrm{DPB} 1^{\star} 02: 01\right.$, $\left.\mathrm{DPA} 1^{\star} 01: 03\right)$ or $10\left(\mathrm{DPB} 1^{\star} 09: 01, \mathrm{DPA}^{\star}{ }^{\star 02: 01)}\right.$ amino acid differences compared to self-DPB ${ }^{\star} 04: 02$. Levels of alloreactivity in our cultured samples were measured based on CD137 upregulation upon restimulation with the relevant alloantigen, and deduction of background levels of the marker against one of the self-alleles (i.e., $\mathrm{DPB} 1^{\star} 04: 01, \mathrm{DPA} 1^{\star} 01: 03$ ).

Figure 1 shows the gating strategy, representative CD137 upregulation plots for each responder, and overall results. The

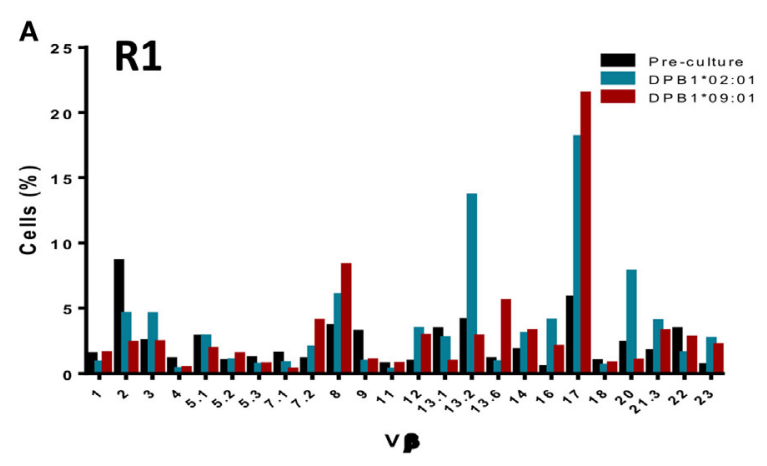

B
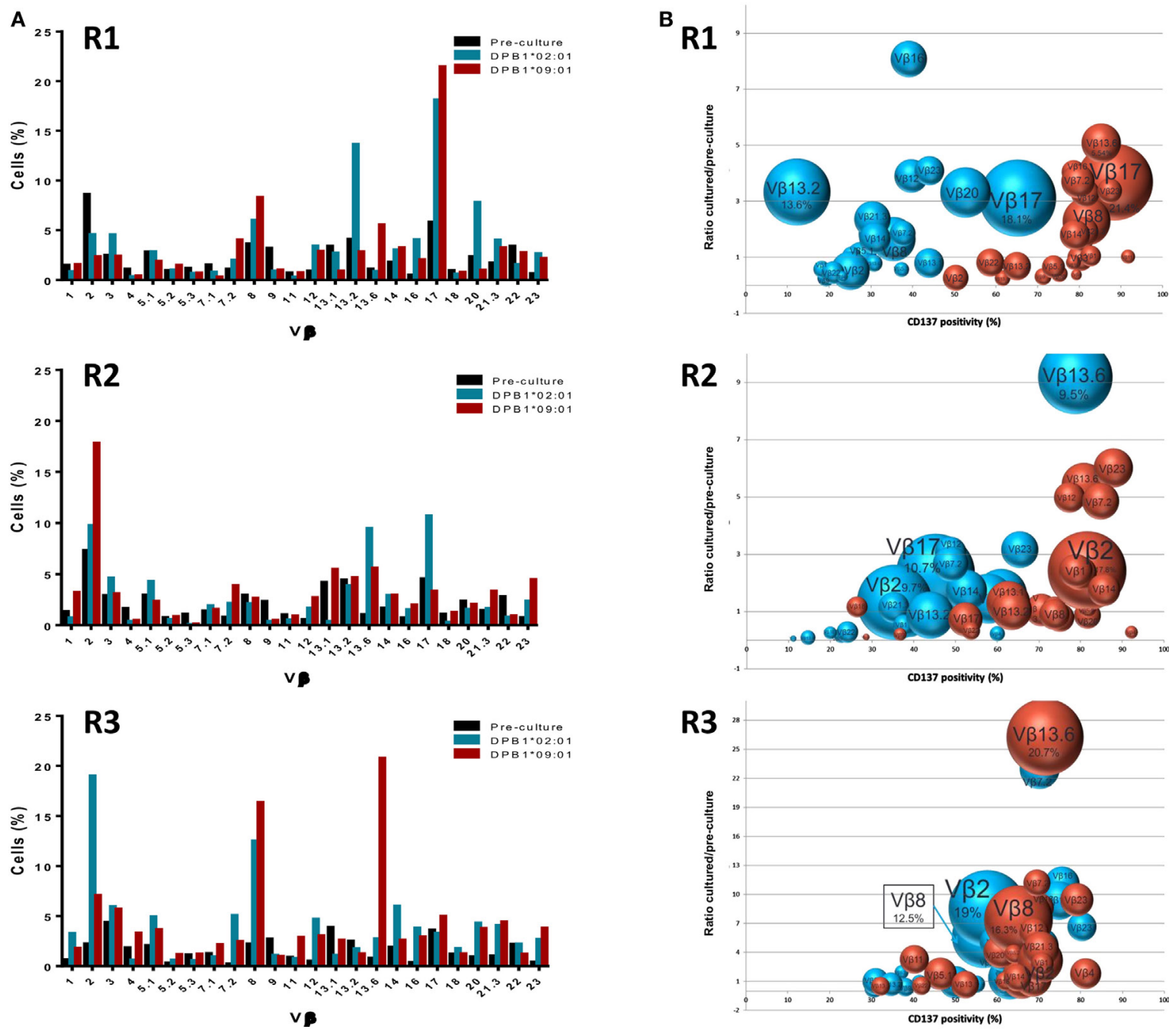

DPB1*09:01

DPB1*02:01
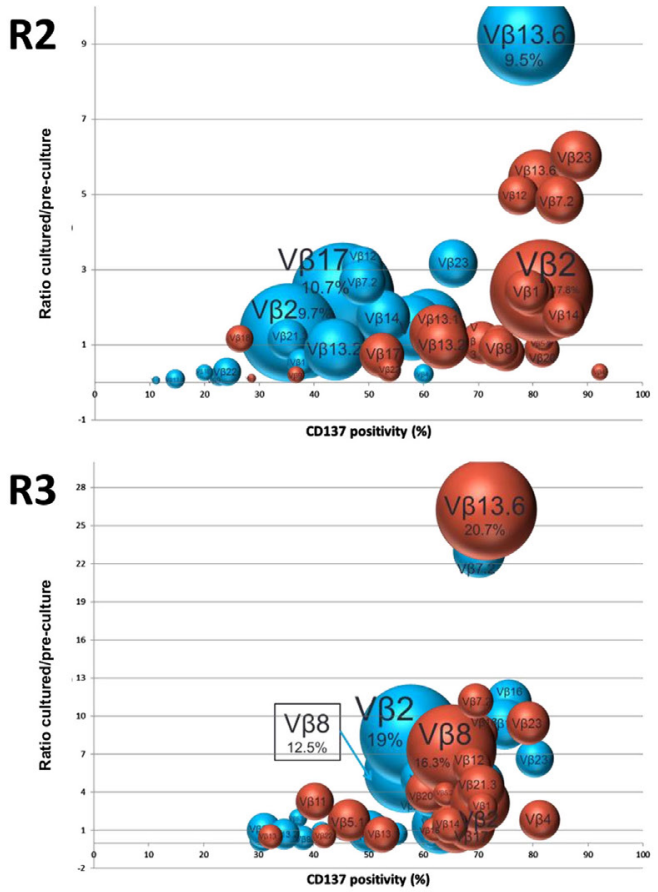

FIGURE 2 | Continued 
C
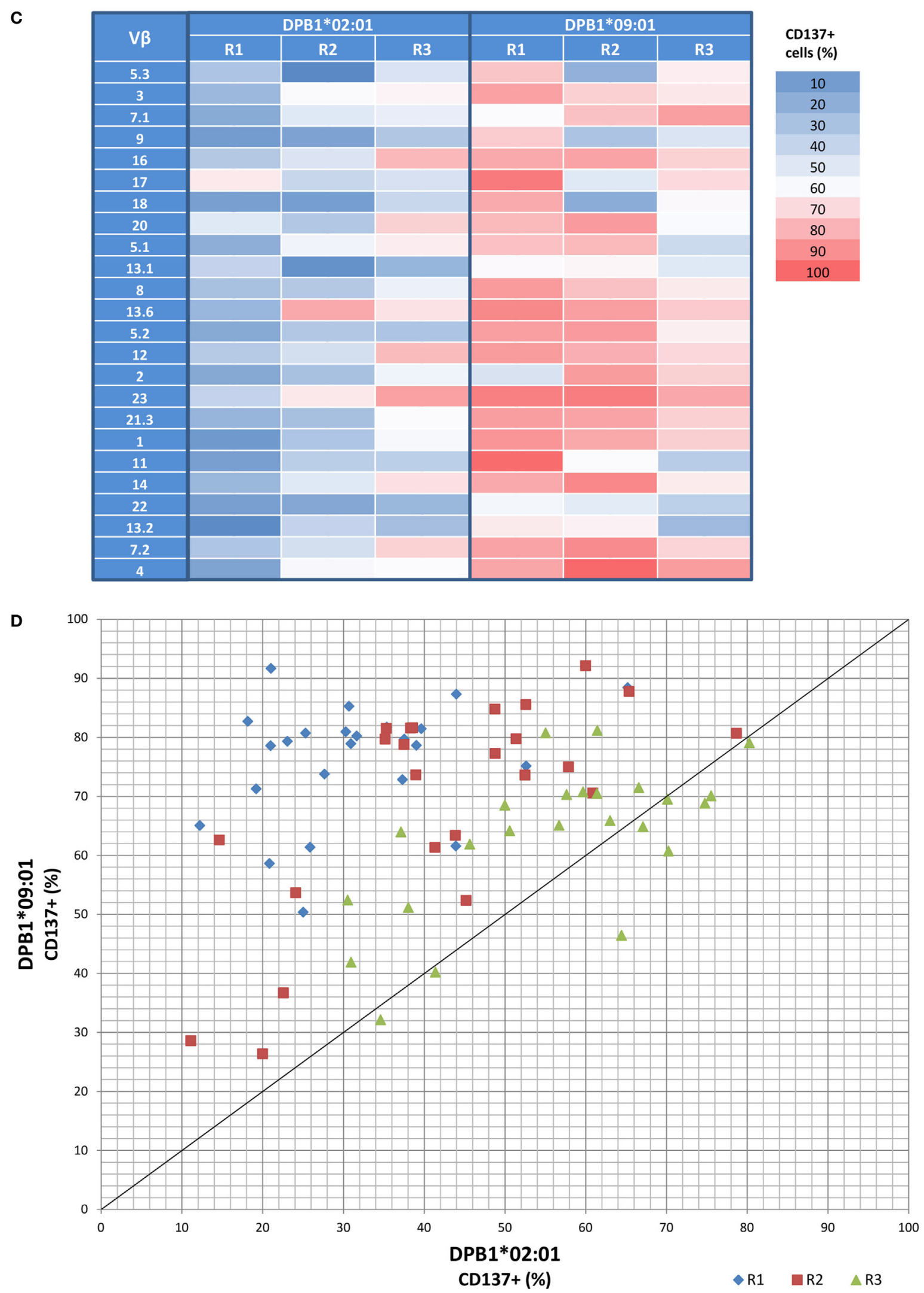

FIGURE 2 | Continued 
FIGURE 2 | Alloresponses against both HLA-DPB1*02:01 and DPB1*09:01 originate from a varied repertoire at the $V \beta$ level, but with stronger responsiveness against the latter. TCR- $\mathrm{V} \beta$ analysis of $24 \mathrm{~V} \beta$ specificities was performed by flow cytometry in CD4+ $T$ cells from three self-DPB1 ${ }^{*} 04: 01,{ }^{*} 04: 02$ responders $(\mathrm{R})$ after 2 weeks of culture with HeLa cells expressing DPB1*02:01 or DPB1*09:01, followed by overnight reincubation with HeLa cells expressing the original alloantigen. (A) Percentage of cells pre-culture and in the CD137+ cultured fractions after restimulation expressing each of the targeted $\mathrm{V} \beta$ families against each alloantigen. (B) Enrichment in the CD137+ cultured fraction vs. pre-culture levels ( $y$ axis) of each of the $V \beta$ specificities was quantified and plotted against CD137 positivity for all cells expressing that $\vee \beta$ family after restimulation ( $x$ axis). The size of each circle represents the share (\% cells positive) of each $\vee \beta$ specificity in the CD137+ $T$ cell receptor repertoire. $\vee \beta$ family dynamics against DPB1*02:01 (blue circles) and DPB1*09:01 (red circles) are shown for each responder. (C) Heat map showing CD137 positivity levels among all cells expressing each V $\beta$ specificity for each of the responders against the two DPB1 alleles. Shown in red are strongly responding $V \beta$ specificities ( $>60 \%$ CD137+ cells after restimulation among all CD4+ cells expressing that specificity). (D) Plot showing the response (CD137 levels) of each of the targeted $V \beta$ specificities against DPB1 ${ }^{\star} 02: 01$ ( $x$ axis) and DPB1*09:01 ( $y$ axis) for each of the three responders. Each dot represents one targeted $V \beta$ specificity for each of the responders. The majority of the $\vee \beta$ specificities respond with higher CD137 levels against DPB1 ${ }^{\star} 09: 01$ than to DPB1 $02: 01$.

TABLE 2 | Immunosequencing data for pre-culture and cultured samples.

\begin{tabular}{|c|c|c|c|c|c|}
\hline Sample & Responder (R) & $\begin{array}{l}\text { Number of productive templates } \\
\text { (total T cells) }\end{array}$ & $\begin{array}{c}\text { Number of rearrangements } \\
\text { (unique } \mathrm{T} \text { cells) }\end{array}$ & $\begin{array}{l}\text { Productive } \\
\text { clonality }\end{array}$ & $\begin{array}{l}\text { Maximum clonal } \\
\text { frequency }(\%)\end{array}$ \\
\hline \multirow[t]{3}{*}{ Pre-culture CD4+ } & $\mathrm{R} 1$ & 180,066 & 98,044 & 0.0599 & 0.38 \\
\hline & $\mathrm{R} 2$ & 167,264 & 116,092 & 0.0406 & 0.53 \\
\hline & R3 & 168,885 & 146,063 & 0.0122 & 0.04 \\
\hline \multirow{3}{*}{$\begin{array}{l}\text { DPB1*02:01-specific } \\
\text { CD137+CD4+ cells }\end{array}$} & $\mathrm{R} 1$ & 7,543 & 720 & 0.3909 & 25.76 \\
\hline & $\mathrm{R} 2$ & 7,874 & 619 & 0.4512 & 26.35 \\
\hline & R3 & 2,530 & 495 & 0.3572 & 27.94 \\
\hline \multirow{3}{*}{$\begin{array}{l}\text { DPB1*09:01-specific } \\
\text { CD137+CD4+ cells }\end{array}$} & $\mathrm{R} 1$ & 26,837 & 1,175 & 0.4596 & 22.51 \\
\hline & $\mathrm{R} 2$ & 1,447 & 251 & 0.2954 & 14.93 \\
\hline & R3 & 9,927 & 959 & 0.3905 & 21.80 \\
\hline
\end{tabular}

response against $\mathrm{DPB} 1^{\star} 02: 01$ was significantly lower than that against $\mathrm{DPB}^{\star} 09: 01$, with mean percentages of alloreactive CD137+CD4+ of 35.2\% (range 23.0-49.6\%) and 61.54\% (range $44.2-70.2 \%)$, respectively.

\section{Diversity of T Cell Responses against DPB1 Alleles at the TCR-V $\beta$ Level}

We first analyzed the TCR diversity among these cells at the level of $\mathrm{V} \beta$ families by using flow cytometric quantification (Figure 2). We observed that all $\mathrm{V} \beta$ specificities tested could be found among the $\mathrm{DPB} 1^{\star} 02: 01$ and $\mathrm{DPB} 1^{\star} 09: 01$-reactive $\mathrm{CD} 4+$ cells (Figure 2A) and that the frequency of the majority (12-16/24 against $\mathrm{DPB} 1^{\star} 02: 01 ; 12-20 / 24$ against $\left.\mathrm{DPB} 1^{\star} 09: 01\right)$ of targeted $\mathrm{V} \beta$ specificities expanded during culture, with average fold expansions of 3.86 against $\mathrm{DPB} 1^{\star} 02: 01$ and 3.50 against $\mathrm{DPB} 1^{\star} 09: 01$. There was a correlation between CD137 positivity in each family and fold expansion from pre-culture levels, with responses against $\mathrm{DPB} 1^{\star}$ 09:01 showing a shift to higher levels of CD137 positivity (Figure 2B). This difference was also reflected in the number of highly reacting $\mathrm{V} \beta$ specificities (i.e., $\mathrm{V} \beta$ for which $>60 \%$ of all cells expressed CD137 after restimulation) against each allele: $1-11 / 24$ against $\mathrm{DPB}^{\star}{ }^{\star} 02: 01$ vs. $18-22 / 24$ against $\mathrm{DPB} 1^{\star}$ 09:01 (Figure $2 \mathrm{C}$ ). In addition, in 63/72 cases the same V $\beta$ family responded with higher CD137 levels against $\mathrm{DPB} 1^{\star} 09: 01$ than to $\mathrm{DPB} 1^{\star} 02: 01$ (overall average $26.1 \%$ higher) (Figure 2D). The cumulative frequency of the top $10 \mathrm{~V} \beta$ specificities was similar for both alleles $\left(63.8 \%\right.$ against $\mathrm{DPB} 1^{\star} 02: 01$ vs.
61.7\% against $\left.\mathrm{DPB} 1^{\star} 09: 01\right)$. Overall, these data at the $\mathrm{V} \beta$ level suggest that responses against a single or multiple amino acid differences in HLA-DP arise from comparable levels of diversity, albeit with overall lower levels of alloreactivity against the more similar allele.

\section{Clonality and Richness of TCR Clones Responding against a Single or Multiple Amino Acid Differences between DPB1 Alleles}

We then analyzed the diversity of alloreactive DPB1-specific CD4+ T cells at the CDR3 level by TCRB immunosequencing. Table 2 shows the summary data for the immunosequencing results. As expected, clonality for the cultured CD137+CD4+ cells (mean 0.39) was higher than in pre-culture samples (average 0.04). However, the diversity among $\mathrm{T}$ cell clones (as defined by their CDR3 sequence at the amino acid level) responding against $\mathrm{DPB} 1^{\star} 02: 01$ was comparable to those responding against $\mathrm{DPB} 1^{\star} 09: 01$, and mean productive clonality of TCR clones responding against $\mathrm{DPB} 1^{\star} 02: 01(0.40$, range $0.36-0.45)$ was similar to that of the clones responding against $\mathrm{DPB}^{\star}{ }^{\star} 09: 01(0.38$, range $0.30-0.46)$ (Figure 3A). The clone richness was also markedly reduced when compared to the pre-culture samples, but did not differ substantially between clones responding against either allele (Figure $3 \mathbf{B}$ ). The share for the top 10 reactive clones in the cultured samples ranged from 54.7 to $66.8 \%$, with no substantial difference 
between cultures responding against $\mathrm{DPB} 1^{\star} 02: 01(59.4 \%$, range $58-62 \%$ ) or $\mathrm{DPB}^{\star} 09: 01$ (mean $60.0 \%$, range $55-67 \%$ ) (Figure 3C). In accordance with these results, the frequency distribution of T-cell clones did not show any major difference between alloresponses against these two alleles (Figure 3D), with similar number of high-frequency clones $(\geq 1 \%): 20,19$, 13 against $\mathrm{DPB} 1^{\star} 02: 01 ; 11,17,13$ against $\mathrm{DPB} 1^{\star} 09: 01$ for R1, R2, and R3, respectively. Finally, analysis of CDR3 length among alloreactive clones revealed no major skewing in the responses against either allele in comparison to pre-culture samples (Figure 4). Overall, these data correlate with the $\mathrm{V} \beta$ analyses and suggest that the responding TCR clones elicited in vitro against a single or multiple amino acid differences in DPB1 do not differ substantially in terms of their size and diversity.

\section{Overlap of TCR Clones Responding against DPB1 Alleles}

We then asked whether there was overlap between individual clone sets responding against either allele and between clones responding against the same allele across individuals. Overall repertoire similarity among cultured samples was low (mean Morisita's index 0.054). There was little overlap between clone sets responding against $\mathrm{DPB} 1^{\star} 02: 01$ and $\mathrm{DPB} 1^{\star} 09: 01$ within the same individual [median Morisita's index: 0.12 (0.005-0.68)] (Figure 5A), and almost no overlap against the same allele across individuals (Figure 5B). At the amino acid level, each individual's clones sets reactive against $\mathrm{DPB} 1^{\star} 02: 01$ and $\mathrm{DPB} 1^{\star} 09: 01$ shared only $38 / 1,204,8 / 571$, and $7 / 1,099$ sequences $(55 / 1,840,13 / 857$, and $7 / 1,447$ nucleotide sequences) (Figure 5A). Analysis of the 10 most frequent sequences revealed almost no sharing between cultures
A

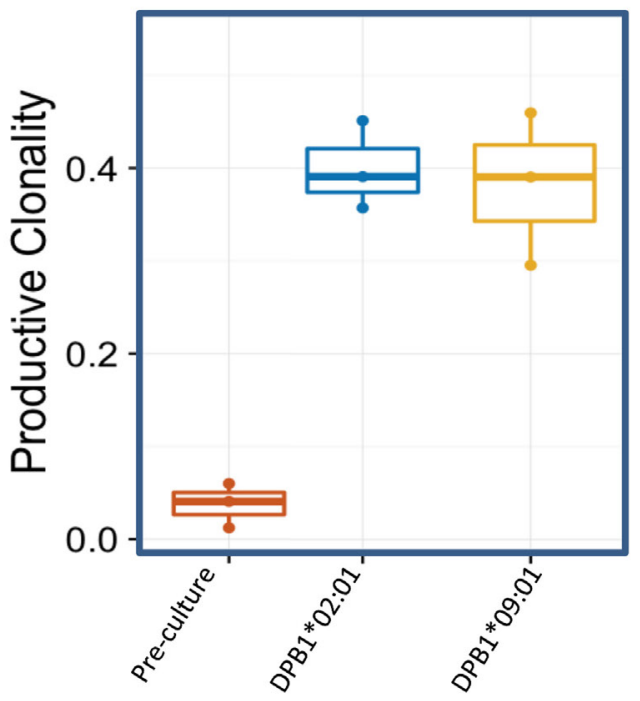

B

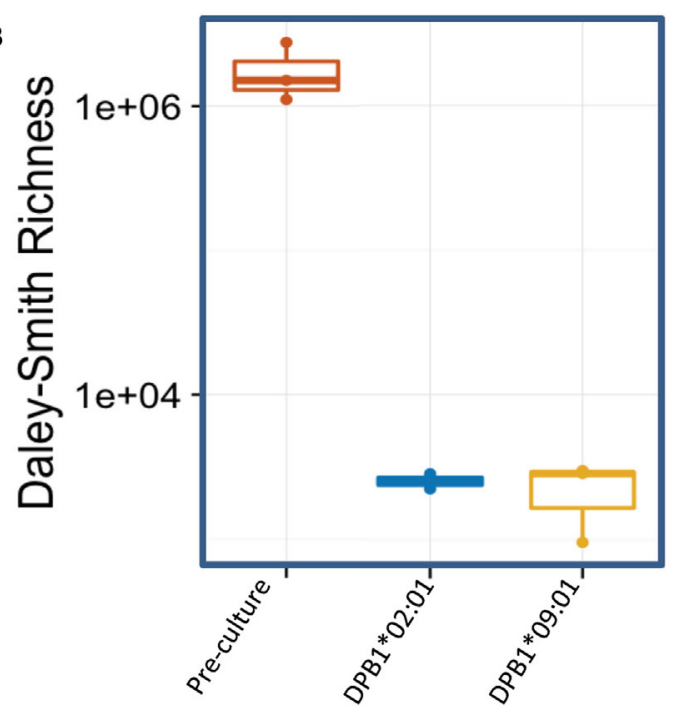

C
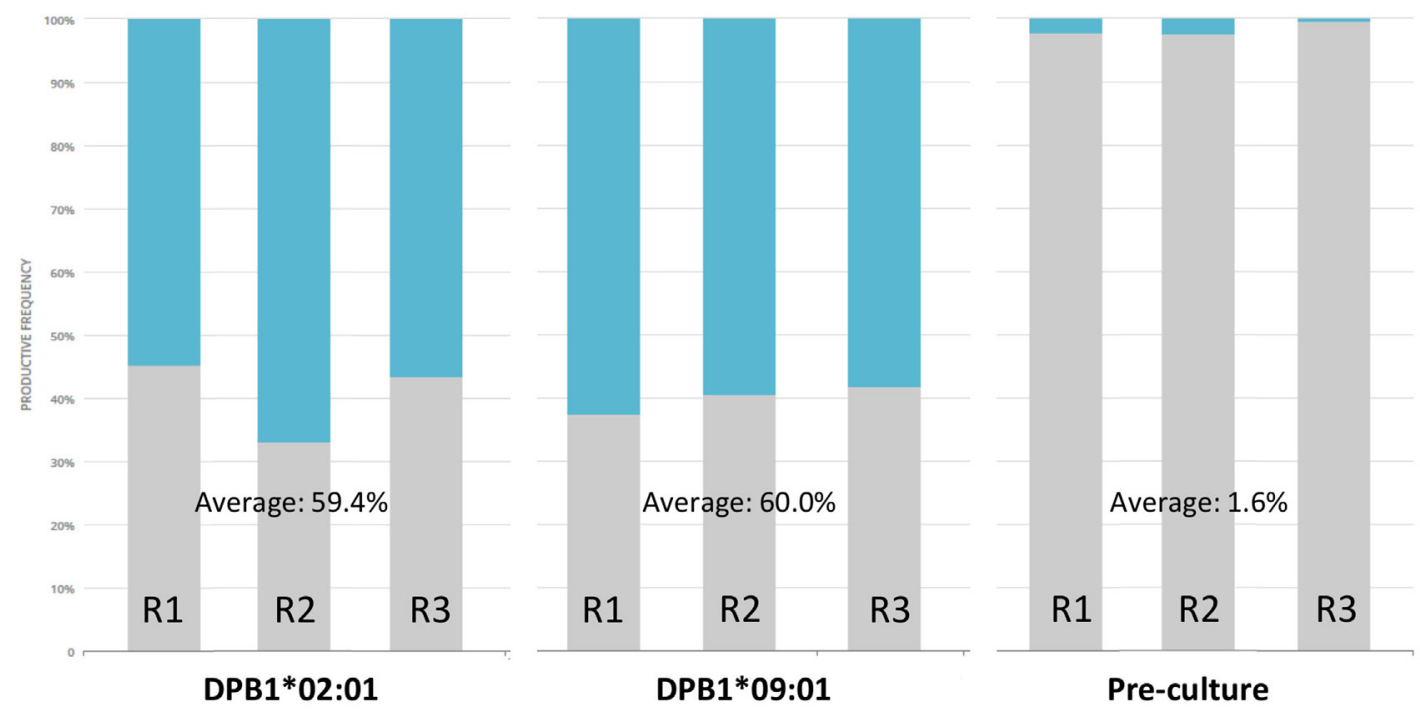

TOP 10 Rearrangements 
R1

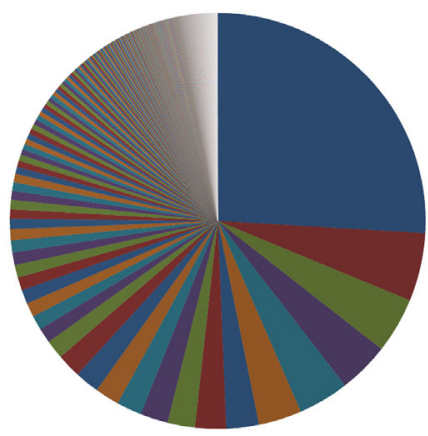

R2

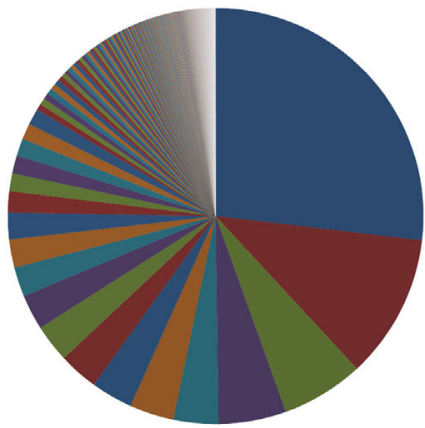

R3

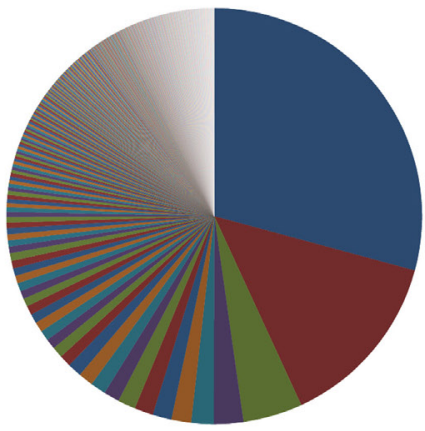

- CAWSVNSNEKLFF

- CSARGRQGAEYF

- CASTLSHYGYTF

- CASARGTEAFF

- CASRRRVGHEQYF

- CASSIGRRGHGNEQFF

- CASSPIGGYGIGNEQFF

- CASSDPAPWVSDEQFF

- CASSYVFSFIINNEQFF

- CASTRDSNEQFF

- CASSLGEAGGYEQYF

- CASSLAHLRQTAYEQYF

- CASKSGLAGIAKNIQYF

- CASSRSPGRDEQFF

- CASRNSQLFYEQYF

- CASRSGEAKYF

- CASSPRVTSSGNTIYF

- CSVILOGNTEAFF

—CASSYPLGGGNQPQHF

- CASSQgPTGTQYF

CASSPRGLITDTOYF

- CSAPGLAGgNEQFF

- CASSFEGEQYF

- CASSLGQGAGQPQHF

- CASNLGDRWLGEQFF

- CASSQGGQGFLGYTF

CASFRGRTEKLFF

- CASSKGVEAFF

- CASRPSGIPDTQYF

- CASSEVDGLDGYTF

\section{DPB1*09:01}

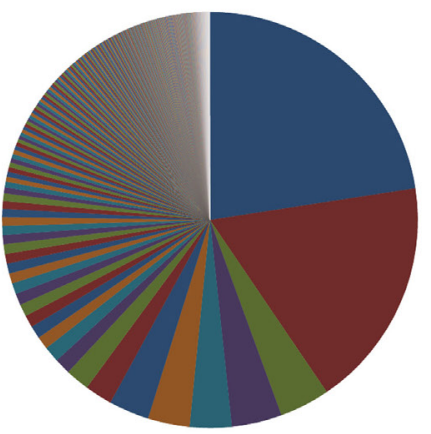

- CAWSVNSNEKLFF

- CASSVTGEVMNTEAFF

- CASSQTSLYEQYV

- CASSRGRDYNSPLHF

- CASSGLGTLGSNQPQHF

- CASSSRRVNSPLHF

- CATSDRGLNYGYTF

- CASSRAADSNEKLFF

- CASTRTGDYGYTF

- CASSYVRALSTDTQYF

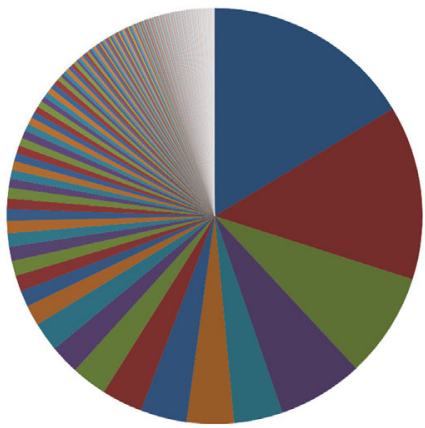

- CASSSPPGETQYF

- CSAATSYNSPLHF

- CASSLRGANEQFF

- CASSLAHLRQTAYEQYF

- CASSLKPGYEQYF

- CASKSGLAGIAKNIQYF

- CSARETGNTEAFF

- CASSPGRSNTGELFF

CASSATRTGGGYGYTF

- CASSPDYSNQPQHF

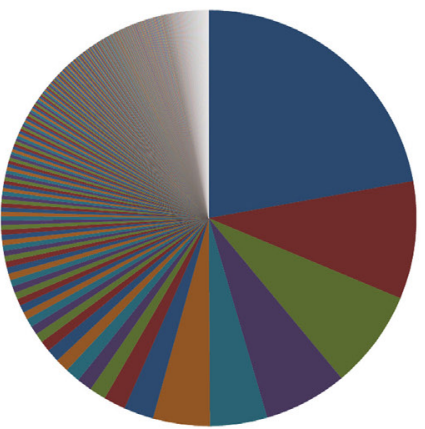

- CASSMEGNQPQHF

- CASSLMSGRNSGEQYF

- CSAKQAEYEQYF

- CASSYGAGASYMNEQFF

- CASSPSTDTQYF

- CASSPRTGEQYF

- CASGTGVNTEAFF

- CSASDRGLYEQYF

- CASSLRLAALYGYTF

n CISGDSYEQYV

FIGURE 3 | Diversity of CD4+ T cell responses against DPB1*02:01 and DPB1*09:01 at the CDR3 level. Immunosequencing of TCRB of sorted CD4+CD137+ cells was performed, and the T cell receptor (TCR) repertoire diversity measures were quantified in CD4+ T cells from three self-DPB1 ${ }^{\star} 04: 01,{ }^{*} 04: 02$ responders (R) after 2 weeks of culture with HeLa cells expressing DPB1 ${ }^{*} 02: 01$ or DPB1*09:01, followed by overnight reincubation with HeLa cells expressing the original alloantigen. Median and interquartile ranges for (A) productive clonality and (B) richness of TCR clones from each responder are plotted, including pre-culture CD4+ cells. (C) Cumulative frequency of the top 10 clones (blue) for each set of alloreactive clones and the pre-culture TCR repertoire is shown. Top 10 clones at the DNA (or amino acid in brackets) level accounted for $54.73 \%$ (56.04\%), 66.83\% (68.71\%), and 56.56\% (58.85\%) against DPB1*02:01, and 62.5\% (63.21\%), 59.5\% (63.99\%), and 58.14\% (60.80\%) against DPB1 ${ }^{\star} 09: 01$ for R1, R2, and R3, respectively. Pre-culture top 10 clones at the DNA (or amino acid in brackets) level accounted for $2.14 \%(2.20 \%)$, 2.39\% (2.45\%), and $0.29 \%(0.31 \%)$ for R1, R2, and R3, respectively. (D) Pie plots showing the frequency distribution for clones at the amino acid level responding against DPB1*02:01 (left plots), and DPB1*09:01 (right plots) for each responder. Listed are the top 10 clones for each sample. The total number of clones at the amino acid level was 481, 409, and 406 against DPB1*02:01, and 761, 170, and 700 against DPB1*09:01 for R1, R2, and R3, respectively.

(Table 3; Figure 3D). Apart from a single nucleotide sequence shared between two individuals responding against $\mathrm{DPB} 1^{\star} 02: 01$ and two clones against $\mathrm{DPB} 1^{\star} 09: 01$ with the same amino acid sequence but different nucleotide sequences, no clone was shared by subjects responding against the same allele (Figure 5B). Overall, these data suggest that, despite showing similar repertoire size metrics, responses against these DPB1 alleles are highly divergent, while responses against the same allele are highly individualized.

\section{Clonal Enrichment and Abundance of TCR Clones Reacting against a Single or Multiple Amino Acid Differences between DPB1 Alleles}

In order to assess clone expansion against a single or multiple amino acid differences in DPB1, we examined their kinetics in terms of enrichment (25) and pre-culture abundance. 


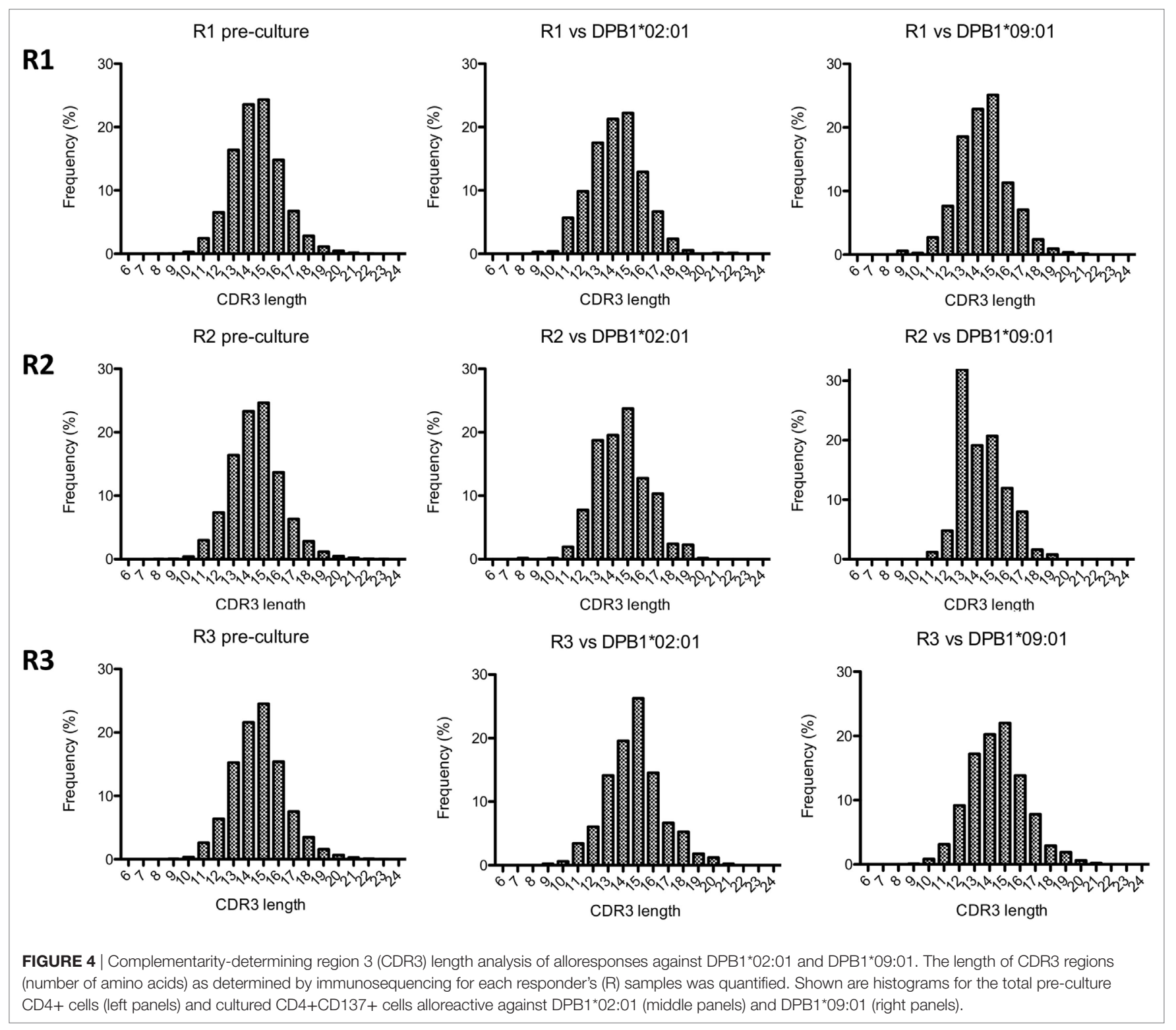

Significantly enriched clones in the cultured samples with respect to the pre-culture repertoires accounted for a large part of the clones responding against $\mathrm{DPB} 1{ }^{\star} 02: 01$ (mean cumulative frequency $82.4 \%$, range $71.82-89.26 \%$ ). This was similar against $\mathrm{DPB} 1^{\star} 09: 01$ (mean $84.2 \%$, range $74.5-93.3 \%$ ). A total of 69,52 , and 33 clones against $\mathrm{DPB}^{\star}{ }^{\star} 02: 01$ and 172,26 , and 105 clones against $\mathrm{DPB} 1^{\star}$ 09:01 showed statistically significant enrichment in cultured samples $(p<0.01)$. For significantly enriched clones detected in the pre-culture samples, average fold expansions against DPB1*02:01 were $866 \times$ (range 15-6,016×), $2,245 \times(6-14,693 \times)$, and $5,350 \times(49-47,194 \times)$, for R1, R2, and $\mathrm{R} 3$, respectively, while among clones responding against DPB $1^{\star} 09: 01$ they were $873 \times(2-32,260 \times), 2,012 \times(11-12,022 \times)$, and $1,396 \times(6-10,786 \times)$ for R1, R2, and R3, respectively. As shown in Figure 6, among clones detected in both the cultured and the pre-culture samples, apart from a few cases where higher frequency clones expanded strongly, those with lower pre-culture frequencies constitute a large part of the cultured clones, with no major difference between DPB1 alleles.

Due to the fact that low-abundance (i.e., rare) alloreactive $\mathrm{T}$ cell clones seem to constitute a major component of alloresponses (29), we evaluated their presence and cumulative frequencies among clones responding against $\mathrm{DPB} 1^{\star} 02: 01$ and compared them to responses against $\mathrm{DPB} 1^{\star}$ 09:01. We defined low-abundance preculture clones as those present in the cultured samples but not detectable in the respective pre-culture samples (Figure 7A). We found that low-abundance clones represented the majority of the clones identified against $\mathrm{DPB} 1^{\star}$ 02:01 (average 68.3\%) and $\mathrm{DPB} 1^{\star}$ 09:01 (average $75.3 \%$ ). However, the mean cumulative frequency of low-abundance clones expanded against $\mathrm{DPB} 1^{\star} 02: 01$ was lower in comparison to those expanded against $\mathrm{DPB} 1^{\star} 09: 01$ (average $36.3 \%$, range $33.6-39.0 \%$ and average $50.6 \%$, range $32.0-71.3 \%$, respectively) (Figure 7B). Overall, these data show that DPB1specific alloreactive clones arise preferentially from low-frequency 


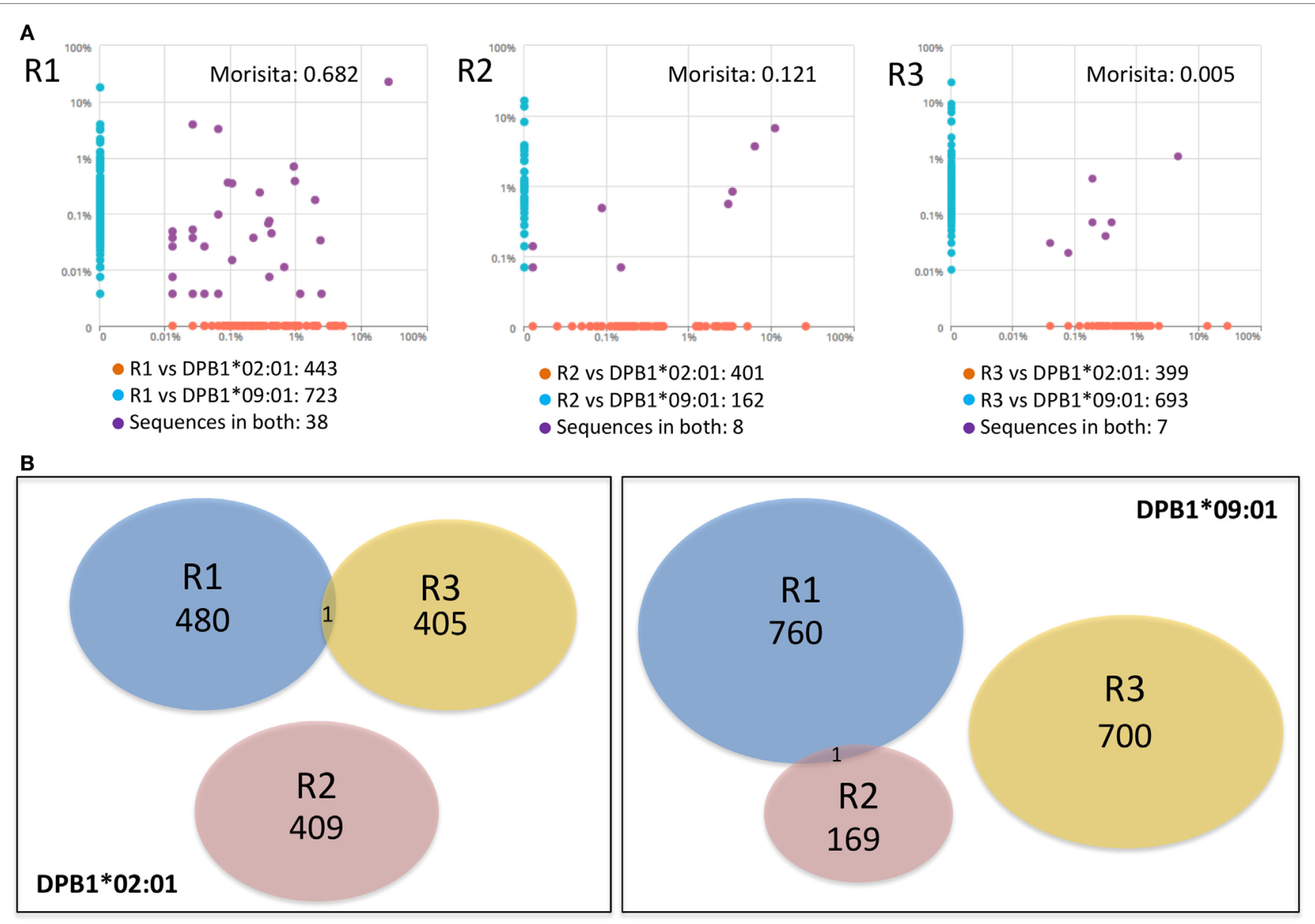

FIGURE 5 | Responses against DPB1*02:01 and DPB1*09:01 alleles are highly divergent and individualized. The sharing of TCRB-CDR3 amino acid sequences among CD4+CD137+ cells responding against DPB1 alleles was compared. (A) Pairwise scatter plots showing the frequency and sharing of clones against each allele in each of the three responders (R). Within each responding individual, there was a low sharing of clones (purple dots) between their responses against DPB1 ${ }^{*} 09: 01$ ( $y$ axis) and DPB1*02:01 ( $x$ axis). Morisita's indexes for each pairwise T cell receptor clone set comparison are shown. (B) Venn diagrams show the sharing of clones across individuals against DPB1 ${ }^{*} 02: 01$ (left panel) and DPB1*09:01 (right panel). The number of unique sequences in each clone set is depicted. Only one DPB1-alloreactive clone was shared across individuals for each allele.

clones, with undetected low-abundance pre-culture T cell clones representing a substantial part of the alloreactive repertoires against HLA-DP molecules, in particular against dissimilar DPB1.

\section{DISCUSSION}

In this study, we have characterized the self-selected (i.e., self-DPB $\left.{ }^{\star} 04: 01,{ }^{\star} 04: 02\right)$ alloreactive $\mathrm{CD} 4+\mathrm{T}$ cell clone sets generated against structurally similar $\left(\mathrm{DPB} 1^{\star} 02: 01\right)$ or dissimilar (DPB1 $\left.{ }^{\star} 09: 01\right)$ HLA-DP molecules in healthy individuals using V $\beta$ immunophenotyping and, for the first time, cutting-edge highresolution immunosequencing of the TCR. Our analyses show that despite quantitative differences in the strength of the in vitro alloresponse, with higher levels of reactivity against the more dissimilar allele, a single amino acid difference in the peptide-binding groove encoded by allogeneic DPB1*02:01 compared to self-DPB1 ${ }^{\star} 04: 02$ is able to generate an array of alloreactive TCR clones of similar broadness and diversity to those elicited by 10 amino acid changes in the peptide-binding groove encoded by allogeneic $\mathrm{DPB} 1^{\star} 09: 01$, with no major differences in clonality and other diversity measures when comparing both alloantigens. In addition, we show a very low overlap between the responses against both alleles at the individual subject level, and essentially no overlap among TCRs responding against the same allele across individuals. Finally, by making use of the unique power of immunosequencing we show that clones with low pre-culture frequencies appear with high frequency among the expanded alloreactive clones and confirm previous observations regarding the relevant role of low-abundance clones in alloreactivity (30). We suggest that this compartment might play a more important role in alloreactivity to more dissimilar DPB1 alleles based on their greater share of the alloreactive clone array elicited by $\mathrm{DPB} 1^{\star}$ 09:01 compared with $\mathrm{DPB} 1^{\star} 02: 01$.

By using specific DPB1 mismatches (i.e., DPB1 ${ }^{\star} 04: 01,{ }^{\star} 04: 02$ vs. $\mathrm{DPB} 1^{\star} 02: 01$ or $\left.\mathrm{DPB} 1^{\star} 09: 01\right)$ involving a single or multiple amino acid changes in the HLA-DP peptide-binding groove with respect to one of the self-selecting alleles (i.e., DPB1 ${ }^{\star} 04: 02$ ), 
TABLE 3 | Top 10 CDR3 amino acid sequences for CD137+CD4+ cells

\begin{tabular}{|c|c|c|c|}
\hline $\begin{array}{l}\text { DPB1*02:01- } \\
\text { specific } \\
\text { CD137+CD4+ } \\
\text { cells }\end{array}$ & $\begin{array}{l}\text { Amino acid } \\
\text { sequence }\end{array}$ & $\begin{array}{l}\text { Frequency } \\
\text { in cultured } \\
\text { sample (\%) }\end{array}$ & $\begin{array}{l}\text { Frequency in } \\
\text { pre-culture } \\
\text { sample (\%) }\end{array}$ \\
\hline \multirow[t]{10}{*}{ R1 } & CAWSVNSNEKLFF & 25.9446 & 0.0405 \\
\hline & CSARGRQGAEYF & 5.2897 & ND \\
\hline & CASTLSHYGYTF & 4.3219 & ND \\
\hline & CASARGTEAFF & 3.9639 & ND \\
\hline & CASRRRVGHEQYF & 3.9374 & 0.0128 \\
\hline & CASSIGRRGHGNEQFF & 3.3674 & 0.0006 \\
\hline & CASSPIGGYGIGNEQFF & 2.5321 & 0.0006 \\
\hline & CASSDPAPWVSDEQFF & 2.3996 & 0.0017 \\
\hline & CASSYVFSFIINNEQFF & 2.1477 & 0.0033 \\
\hline & CASTRDSNEQFF & 2.1344 & 0.0006 \\
\hline \multirow[t]{10}{*}{ R2 } & CASSLGEAGGYEQYF & 26.8732 & 0.0018 \\
\hline & CASSLAHLRQTAYEQYF & 11.2395 & 0.5548 \\
\hline & CASKSGLAGIAKNIQYF & 6.4135 & 0.0006 \\
\hline & CASSRSPGRDEQFF & 5.2705 & ND \\
\hline & CASRNSQLFYEQYF & 3.4798 & ND \\
\hline & CASRSGEAKYF & 3.4417 & 0.0048 \\
\hline & CASSPRVTSSGNTIYF & 3.2512 & ND \\
\hline & CSVILQGNTEAFF & 3.0734 & 0.0012 \\
\hline & CASSYPLGGGNQPQHF & 2.9337 & 0.0006 \\
\hline & CASSQGPTGTQYF & 2.7305 & ND \\
\hline \multirow[t]{10}{*}{ R3 } & CASSPRGLITDTQYF & 29.2095 & 0.0006 \\
\hline & CSAPGLAGGNEQFF & 13.9130 & 0.0006 \\
\hline & CASSFEGEQYF & 4.6245 & 0.0012 \\
\hline & CASSLGQGAGQPQHF & 2.2925 & 0.0012 \\
\hline & CASNLGDRWLGEQFF & 1.7391 & ND \\
\hline & CASSQGGQGFLGYTF & 1.5415 & ND \\
\hline & CASFRGRTEKLFF & 1.4625 & ND \\
\hline & CASSKGVEAFF & 1.4625 & 0.0006 \\
\hline & CASRPSGIPDTQYF & 1.3834 & ND \\
\hline & CASSEVDGLDGYTF & 1.2253 & 0.0006 \\
\hline $\begin{array}{l}\text { DPB1*09:01- } \\
\text { specific } \\
\text { CD137+CD4+ } \\
\text { cells }\end{array}$ & Amino acid sequence & $\begin{array}{l}\text { Frequency } \\
\text { in cultured } \\
\text { sample (\%) }\end{array}$ & $\begin{array}{l}\text { Frequency in } \\
\text { pre-culture } \\
\text { sample (\%) }\end{array}$ \\
\hline \multirow[t]{10}{*}{ R1 } & CAWSVNSNEKLFF & 22.5659 & 0.0405 \\
\hline & CASSVTGEVMNTEAFF & 17.93 & 0.0006 \\
\hline & CASSQTSLYEQYV & 3.9200 & ND \\
\hline & CASSRGRDYNSPLHF & 3.8976 & 0.0061 \\
\hline & CASSGLGTLGSNQPQHF & 3.2530 & 0.0006 \\
\hline & CASSSRRVNSPLHF & 3.2455 & 0.0072 \\
\hline & CATSDRGLNYGYTF & 3.1337 & 0.0028 \\
\hline & CASSRAADSNEKLFF & 2.1426 & 0.0061 \\
\hline & CASTRTGDYGYTF & 1.8556 & ND \\
\hline & CASSYVRALSTDTQYF & 1.2632 & ND \\
\hline \multirow[t]{5}{*}{ R2 } & $\begin{array}{l}\text { CASSSPPGETQYF } \\
\text { CSAATSYNSPI HF }\end{array}$ & $\begin{array}{l}16.3787 \\
13.5453\end{array}$ & 0.0036 \\
\hline & $\begin{array}{l}\text { CSAATSYNSPLHF } \\
\text { CASSLRGANEQFF }\end{array}$ & $\begin{array}{l}13.5453 \\
8.1548\end{array}$ & $\begin{array}{l}\text { ND } \\
0.0006\end{array}$ \\
\hline & CASSLAHLRQTAYEQYF & 6.6344 & 0.5548 \\
\hline & CASSLKPGYEQYF & 3.8010 & ND \\
\hline & CASKSGLAGIAKNIQYF & 3.6628 & 0.0006 \\
\hline
\end{tabular}

(Continued)
TABLE 3 | Continued

\begin{tabular}{|c|c|c|c|}
\hline $\begin{array}{l}\text { DPB1*09:01- } \\
\text { specific } \\
\text { CD137+CD4+ } \\
\text { cells }\end{array}$ & Amino acid sequence & $\begin{array}{l}\text { Frequency } \\
\text { in cultured } \\
\text { sample }(\%)\end{array}$ & $\begin{array}{l}\text { Frequency in } \\
\text { pre-culture } \\
\text { sample (\%) }\end{array}$ \\
\hline & CSARETGNTEAFF & 3.5936 & ND \\
\hline & CASSPGRSNTGELFF & 3.1790 & ND \\
\hline & CASSATRTGGGYGYTF & 2.7643 & 0.0042 \\
\hline & CASSPDYSNQPQHF & 2.2806 & 0.0018 \\
\hline \multirow[t]{10}{*}{ R3 } & CASSMEGNQPQHF & 22.1416 & ND \\
\hline & CASSLMSGRNSGEQYF & 9.1468 & 0.0024 \\
\hline & CSAKQAEYEQYF & 7.6760 & ND \\
\hline & CASSYGAGASYMNEQFF & 6.4874 & 0.0006 \\
\hline & CASSPSTDTQYF & 4.4525 & 0.0065 \\
\hline & CASSPRTGEQYF & 4.4223 & ND \\
\hline & CASGTGVNTEAFF & 2.3169 & ND \\
\hline & CSASDRGLYEQYF & 1.7024 & 0.0006 \\
\hline & CASSLRLAALYGYTF & 1.2894 & ND \\
\hline & CISGDSYEQY & 1.1685 & 0.0006 \\
\hline
\end{tabular}

CDR3, complementarity-determining region 3; ND, not detected.

we sought to dissect the effect of the extent of variation in this region of the HLA-DP molecule exerted indirectly via thymic selection on the diversity of clones expanded from the alloreactive TCR repertoire. $\mathrm{DPB} 1^{\star} 09: 01$ and $\mathrm{DPB} 1^{\star} 04: 01{ }^{*} 04: 02$ differ at 13 and 10 positions in exon 2 , respectively. It is expected that the peptide repertoires of these molecules differ substantially, providing a plausible explanation for strong alloreactivity and diverse TCR responses observed among self-DPB $1^{\star} 04: 01,{ }^{*} 04: 02$ individuals. On the other hand, the DPB $1^{*} 02: 01$ exon 2 differs from $\mathrm{DPB} 1^{\star} 04: 02$ only at position 69 (E69K). This makes it likely that the peptide repertoires of these two molecules overlap to a certain extent. Indeed, analysis of the peptide binding motifs for $\mathrm{DPB1}^{*}$ 02:01 (31) and DPB1*04:02 (unpublished data, manuscript in preparation) show that peptide position $\mathrm{P} 4$, which interacts with the pocket formed in part by the side chain of position 69 on the alpha-helix of the DP beta polypeptide, is the only position that seems to differ significantly between these two alleles, with $\mathrm{DPB} 1^{\star} 02: 01$ having affinity for lysine and $\mathrm{DPB} 1^{\star} 04: 02$ for glutamic acid at P4. Importantly, position 69 on the $\mathrm{DPB1} 1^{\star} 02: 01$ molecule has been shown to impact the recognition of this molecule by monoclonal antibodies (32), bone marrow recipientdonor mixed-lymphocyte reactions (10), and the lysis of DPB ${ }^{\star} 02$ :01-expressing cells by alloreactive $T$ cell clones $(33,34)$. Moreover, mutation of position 69 in DPB $1^{*} 02: 01$ was shown to impact the class II-associated invariant chain-derived peptide binding affinities of pockets 4 and 6 (35). Interestingly, this position of the DPB1 molecule and the specific amino acid E69K change have been previously identified as having a strong impact on the generation of alloreactivity against DPB $1^{\star} 09: 01$ (13).

Of note, some studies have reported that class I HLA molecules with numerous sequence differences do not elicit an allogeneic cytotoxic lymphocyte response (36) and that such highly diverged mismatches might be acceptable in HSCT (37). We have not observed this phenomenon in our CD4+ assays, neither with $\mathrm{DPB1}{ }^{\star}$ 09:01 nor with other alleles having several amino acid 


\section{DPB1*02:01}

\section{R1}

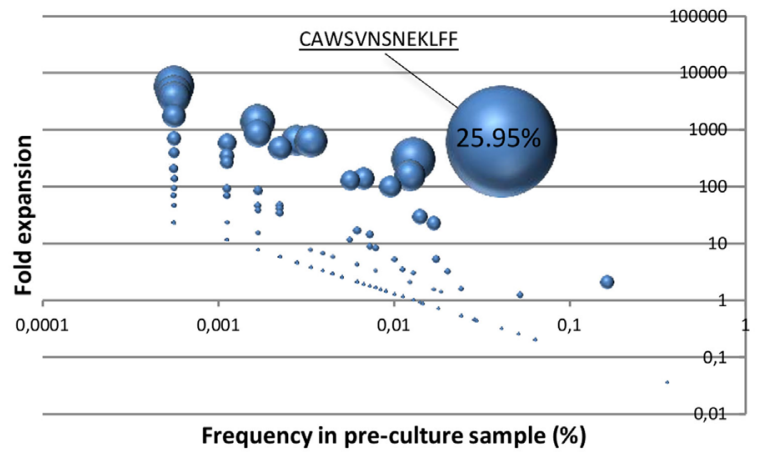

R2

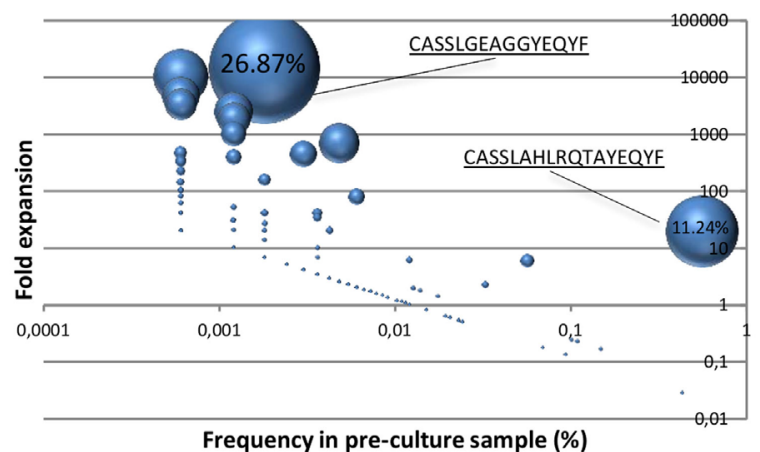

R3

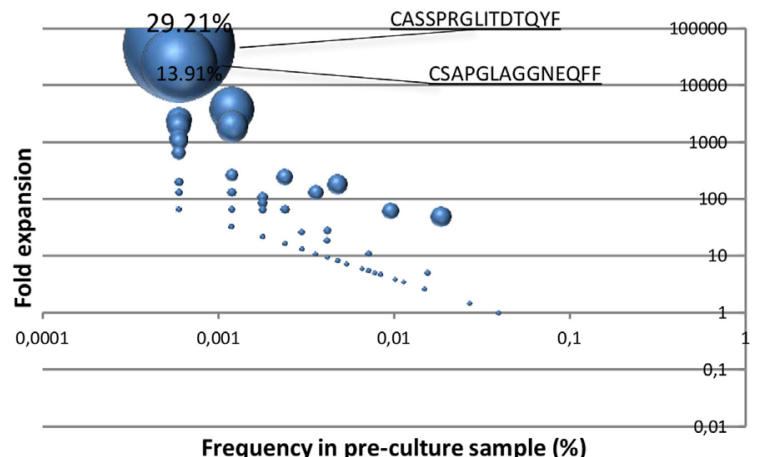

DPB1*09:01
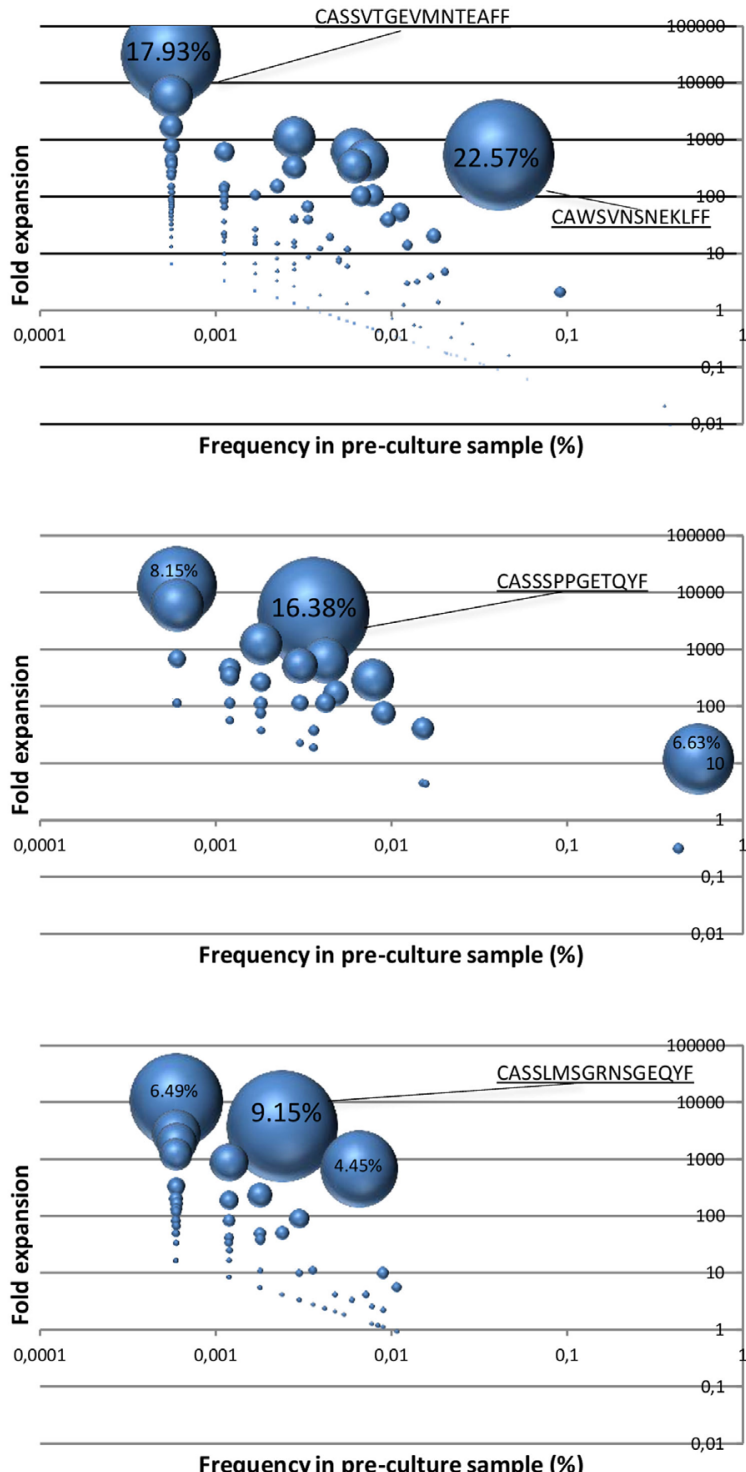

FIGURE 6 | Expansion of DPB1-specific alloreactive clones detected in pre-culture samples. Fold expansion among alloreactive T cell clones present in the cultured samples and that could be detected in the pre-culture samples for each responder (R) was quantified and plotted ( $y$ axis) against their frequency in the pre-culture sample ( $x$ axis). The size of the circle represents the share of each clone in the total cultured set. Highest values (\%) are indicated for each sample. Left panels, clones responding against DPB1*02:01; right panels, clones responding against DPB1*09:01. As shown in Figure 7A (purple dots), 177, 146, and 92 clones against DPB1 ${ }^{\star} 02: 01$, and 249,43 , and 112 clones against DPB1 ${ }^{\star} 09: 01$ were detected in both the cultured and the pre-culture samples for R1, R2, and R3, respectively.

differences when compared to the autologous alleles (unpublished data). Intuitively, more amino acid differences in the peptidebinding grove would generate more divergent peptide repertoires resulting in a lower indirect effect of thymic selection and higher alloreactivity, something that lies at the basis of the TCE model.

In the context of allogeneic HSCT, compatibility between donor and recipient for polymorphic HLA plays a central role in the balance between the detrimental graft-vs.-host and therapeutic graft-vs.-leukemia effects $(38,39)$, both mediated mainly by alloreactive T cell responses. Because of this, the search of HLA permissive mismatches, which contribute to cure the patient's malignancy while reducing the toxicity of the transplant, is a major goal in HSCT (40). Permissiveness to DPB1 mismatches is now a well-established phenomenon in HSCT, both clinically $(14,15)$ and in vitro $(9,12,41)$, with permissive mismatches (i.e., those involving two alleles of the same T cell epitope, TCE, group, and that share structural similarities) conferring significantly lower risks of relapse without significant increases in non-relapse mortality when compared to DPB1 allele matches after HSCT for hematologic malignancies $(14,42,43)$. 

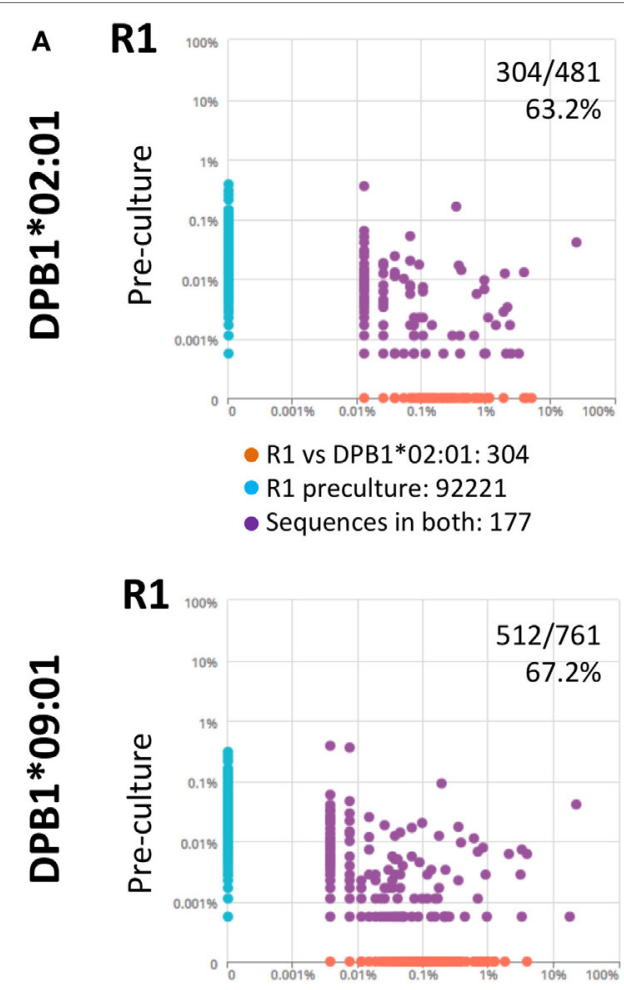

- R1 vs DPB1*09:01: 512

- R1 preculture: 92149

- Sequences in both: 249

B $\quad \mathbf{R} \mathbf{1}$

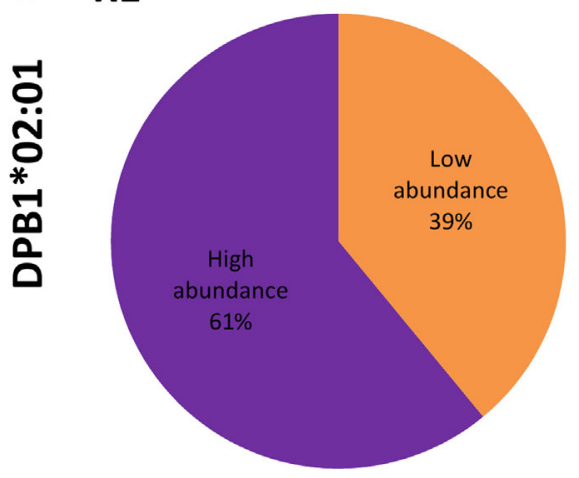

R1

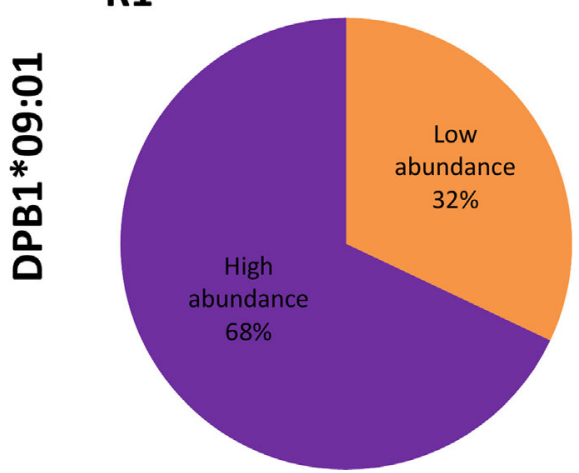

R2

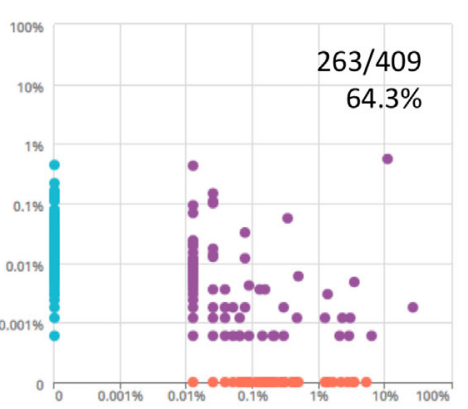

- R2 vs DPB1*02:01: 263

- R2 preculture: 109236

- Sequences in both: 146

R2

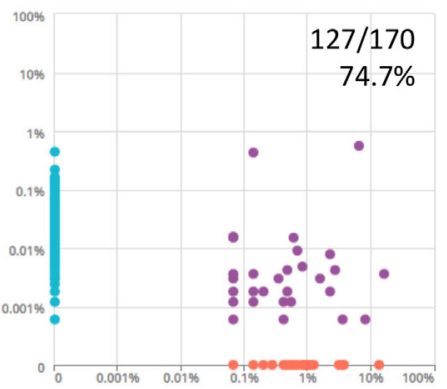

R2 vs DPB1*02:01: 127

- R2 preculture: 109339

- Sequences in both: 43

R2

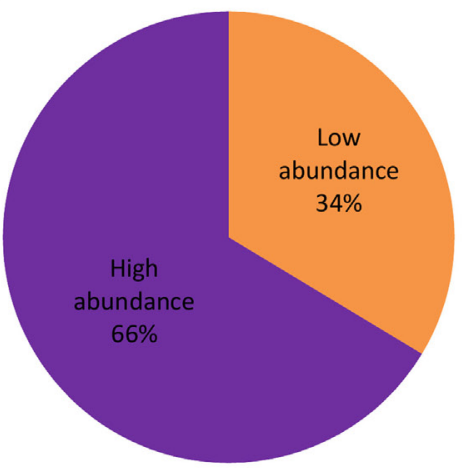

R2

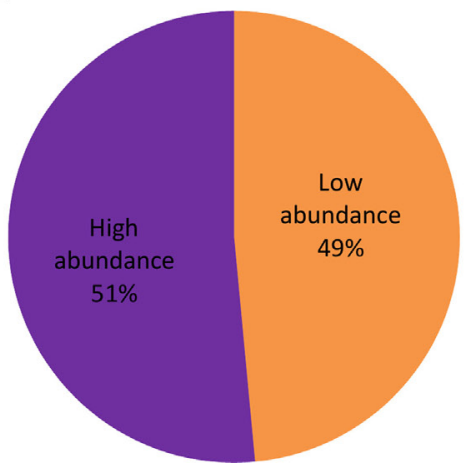

R3

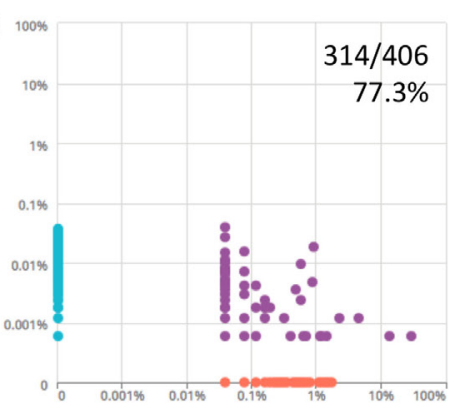

- R3 vs DPB1*02:01: 314

- R3 preculture: 138115

- Sequences in both: 92

R3

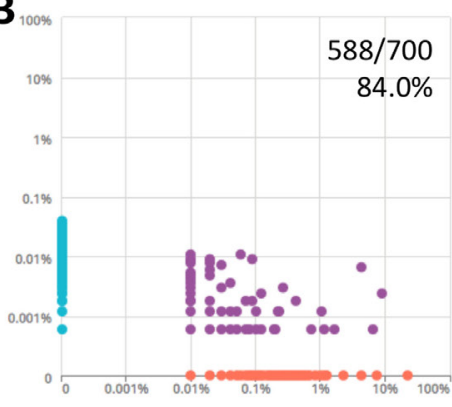

- R3 vs DPB1*02:01: 588

- R3 preculture: 138095

- Sequences in both: 112

R3

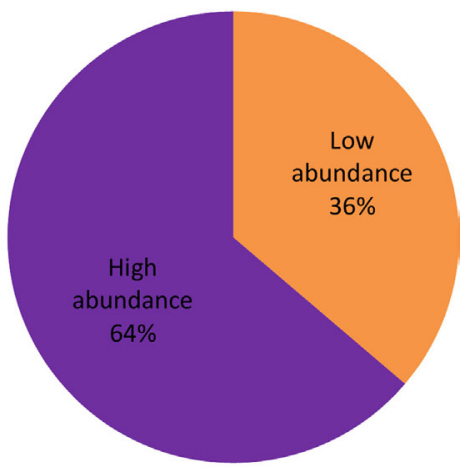

R3

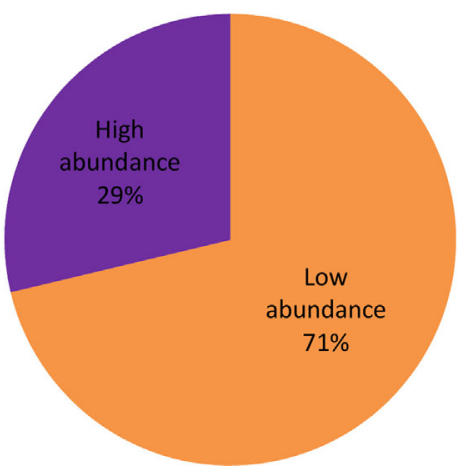

FIGURE 7 | Continued 
FIGURE 7 | Low abundance pre-culture T cell clones represent a substantial part of the alloreactive clones elicited against HLA-DPB1 molecules with higher share against DPB1*09:01. (A) Clone (CDR3 amino acid) pairwise scatter plots between pre-culture repertoires and CD4+CD137+ cells responding against DPB1*02:01 (top panels) and DPB1*09:01 (bottom panels) are shown for each responder (R). Low-abundance DPB1-alloreactive clones (orange dots in the pairwise scatter plots) were defined as those present in the cultured sample ( $x$ axis) and not detected in the respective pre-culture repertoire ( $y$ axis). The number and percentage of low abundance clones relative to the total number of clones detected in the cultured sample are shown. (B) The share (cumulative frequency) of low abundance clones was quantified for clones responding against DPB1*02:01 (top panels) or DPB1 $09: 01$ (bottom panels) in each subject. The average cumulative frequency for low-abundance clones against DPB1 ${ }^{\star} 02: 01$ and DPB1 ${ }^{*} 09: 01$ was 36.3 and $50.6 \%$, respectively.

Clinically, a mismatch involving a donor who is self$\mathrm{DPB} 1{ }^{\star} 04: 01,{ }^{\star} 04: 02$ and a patient bearing $\mathrm{DPB} 1{ }^{\star} 02: 01$ would currently be considered permissive, whereas one involving a patient with a self-DPB $1^{*}$ 09:01 is considered non-permissive. Our data show that, contrary to the strength of the alloreactive response, the diversity of the alloreactive clones elicited by such a permissive mismatch does not seem to be impacted by the number of amino acid differences in the peptide-binding groove. This feature is desirable for the therapeutic effect of HSCT: moderate alloreactivity levels combined with a sufficiently broad repertoire maximizing the capacity of donor-derived $\mathrm{T}$ cells of effectively recognizing malignant patient cells while minimizing GvHD.

Since permissiveness was not predicted by significant differences in terms of the size of the set of responding TCR clones, it is possible that a qualitative characteristic of the HLA-TCR interaction influencing events downstream of TCR recognition $(44,45)$ and shaped by thymic selection might be responsible for this phenomenon $(16,46)$. Thymic education in a self-DPB $1^{\star} 04: 01,{ }^{\star} 04: 02$ individual could have an indirect effect on the allogeneic repertoire capable of reacting to a structurally related molecule such as $\mathrm{DPB1}{ }^{\star} 02: 01$, by reducing the affinity of the binding to the allogeneic molecule. This would not result in more restricted reacting TCR repertoires but in lower activation and proliferation of the T cells. We cannot, however, rule out that TCR repertoire breadth plays a role in permissiveness to other specific allelic combinations. Moreover, $\mathrm{DPB} 1^{\star} 02: 01 \mathrm{might}$ still represent a separate TCE group (47) and hence behave differently with respect to other alleles sharing similarity to $\mathrm{DPB} 1^{\star} 04: 02$. More research into this question is warranted.

Interestingly, low-abundance $\mathrm{T}$ cell clones, which have been shown to constitute a significant amount of the alloreactive response in vitro (29) and in vivo (30), seem to represent a higher proportion of the TCR clone sets against $\mathrm{DPB} 1^{\star} 09: 01$ than against DPB $1^{\star} 02: 01$. A possible explanation for this observation could be that a more functionally distant allele such as $\mathrm{DPB} 1^{\star} 09: 01 \mathrm{might}$ elicit stronger TCR signaling that could help to beat the threshold to extract these specificities from the deep pre-culture repertoire thanks to better proliferative signals.

Recent reports have shown a potential effect of differential 3'UTR-controlled expression levels on permissiveness of DPB1 mismatches in the context of HSCT $(48,49)$. This model would not play a role in the results presented in this study since the HeLa cell system utilized does not include the 3'UTR region of this gene (18). However, we cannot dismiss a potential effect of this model on the alloreactive TCR repertoires against HLA-DP molecules in a physiological setting.

Our study is limited by the number of subjects included, the use of the HeLa system (i.e., of a non-physiological antigen presenting cell to stimulate our alloreactive T cells), and the use of total CD4+ responder T cells. Although we have been unable to identify any "public" TCR clones responding against $\mathrm{DPB} 1^{\star} 02: 01$ and/or DPB1*09:01, a larger study with a significantly larger number of subjects would be required to rule out the existence of such clones in the population. Similarly, the analysis of a potential effect of responder age and the frequency of memory CD4+ $\mathrm{T}$ cells in their repertoire on the clonality of HLA-DP alloreactive cells would require a larger number of samples. The use of HeLa cells transduced to express specific DPB1 alleles, although extremely useful experimentally, could skew our results due to the underlying peptidome of this non-hematopoietic tumor cell line. Moreover, we have not addressed the question whether the naïve and memory CD4+ repertoires could behave differently in alloresponses, something that has been previously suggested $(50,51)$. In addition, despite the high level of over $90 \%$ purity of our CD137+ samples, a confounding effect of contaminating CD137- cells especially on rare CDR3 sequences cannot be ruled out. Finally, CD4+ T cells reactive against HLA class I molecules have been described $(52,53)$. However, their impact on our results, if any, must be minimal, since very low levels of activation were observed when the responder cells were restimulated with the HeLa expressing the autologous DPB1 allele, which would express the same class I molecules as those transduced with the allogeneic molecules.

In conclusion, our study, the first one to comparatively address TCR diversity in responses to similar or dissimilar allogeneic HLA-DP molecules by NGS immunosequencing, shows proofof-principle evidence for the novel concept that limited strength alloreactivity can coexist with broad TCR diversity, providing a potential platform for clinically favorable DPB1 mismatches in allogeneic HSCT. The potential role for in vitro pre-transplant low-abundance clones, revealed solely through the power of NGS immunosequencing, as personalized clinical biomarkers in HSCT needs to be further clarified by in vivo tracking of expanded clones in patients with alloreactivity against DPB1 mismatches.

\section{ETHICS STATEMENT}

This study was carried out in accordance with the recommendations of University Hospital Essen with written informed consent from all subjects in accordance with the Declaration of Helsinki. The protocol was approved by the local Ethics Committee of University Hospital Essen.

\section{AUTHOR CONTRIBUTIONS}

EA-B, PC, and KF designed the study; EA-B, PC, MM, and TM performed experiments; MA contributed advice on TCR immunosequencing experiments; $\mathrm{PB}$ and JF produced the transduced HeLa cells; EA-B, JR, MV, and EY performed statistical analysis; 
PH contributed PBMC from healthy blood donors and their HLA typing; and EA-B and KF wrote the manuscript.

\section{ACKNOWLEDGMENTS}

The authors would like to thank Prof. Monika Lindemann (Institute for Transfusion Medicine, University Hospital Essen) for assistance with the interferon- $\gamma$ Elispot assays.

\section{REFERENCES}

1. Ford WL, Atkins RC. The proportion of lymphocytes capable of recognizing strong transplantation antigens in vivo. Adv Exp Med Biol (1973) 29(0):255-62. doi:10.1007/978-1-4615-9017-0_37

2. DeWolf S, Shen Y, Sykes M. A new window into the human alloresponse. Transplantation (2016) 100(8):1639-49. doi:10.1097/TP.0000000000001064

3. Felix NJ, Allen PM. Specificity of T-cell alloreactivity. Nat Rev Immunol (2007) 7(12):942-53. doi:10.1038/nri2200

4. Wang Y, Singh NK, Spear TT, Hellman LM, Piepenbrink KH, McMahan RH, et al. How an alloreactive T-cell receptor achieves peptide and MHC specificity. Proc Natl Acad Sci U S A (2017) 114(24):E4792-801. doi:10.1073/pnas.1700459114

5. Fleischhauer K, Kernan NA, O'Reilly RJ, Dupont B, Yang SY. Bone marrow-allograft rejection by $\mathrm{T}$ lymphocytes recognizing a single amino acid difference in HLA-B44. N Engl J Med (1990) 323(26):1818-22. doi:10.1056/ NEJM199012273232607

6. Keever CA, Leong N, Cunningham I, Copelan EA, Avalos BR, Klein J, et al. HLA-B44-directed cytotoxic T cells associated with acute graft-versus-host disease following unrelated bone marrow transplantation. Bone Marrow Transplant (1994) 14(1):137-45.

7. Joris MM, van Rood JJ, Roelen DL, Oudshoorn M, Claas FH. A proposed algorithm predictive for cytotoxic T cell alloreactivity. J Immunol (2012) 188(4):1868-73. doi:10.4049/jimmunol.1102086

8. Joris MM, Lankester AC, von dem Borne PA, Kuball J, Bierings M, Cornelissen JJ, et al. Translating in vitro prediction of cytotoxic $\mathrm{T}$ cell alloreactivity to hematopoietic stem cell transplantation outcome. Transpl Immunol (2014) 30(2-3):59-64. doi:10.1016/j.trim.2013.08.006

9. Sizzano F, Zito L, Crivello P, Crocchiolo R, Vago L, Zino E, et al. Significantly higher frequencies of alloreactive $\mathrm{CD} 4+\mathrm{T}$ cells responding to nonpermissive than to permissive HLA-DPB1 T-cell epitope disparities. Blood (2010) 116(11):1991-2. doi:10.1182/blood-2010-05-284687

10. Nicholson I, Varney M, Kanaan C, Grigg A, Szer J, Tiedemann K, et al. Alloresponses to HLA-DP detected in the primary MLR: correlation with a single amino acid difference. Hum Immunol (1997) 55(2):163-9. doi:10.1016/ S0198-8859(97)00091-8

11. Cesbron A, Moreau P, Milpied N, Harousseau JL, Muller JY, Bignon JD. Crucial role of the third and fourth hypervariable regions of HLA-DPB1 allelic sequences in the mixed lymphocyte reaction. Hum Immunol (1992) 33(3):202-7. doi:10.1016/0198-8859(92)90072-U

12. Zino E, Frumento G, Marktel S, Sormani MP, Ficara F, Di Terlizzi S, et al. A T-cell epitope encoded by a subset of HLA-DPB1 alleles determines nonpermissive mismatches for hematologic stem cell transplantation. Blood (2004) 103(4):1417-24. doi:10.1182/blood-2003-04-1279

13. Crivello P, Zito L, Sizzano F, Zino E, Maiers M, Mulder A, et al. The impact of amino acid variability on alloreactivity defines a functional distance predictive of permissive HLA-DPB1 mismatches in hematopoietic stem cell transplantation. Biol Blood Marrow Transplant (2015) 21(2):233-41. doi:10.1016/j. bbmt.2014.10.017

14. Fleischhauer K, Shaw BE, Gooley T, Malkki M, Bardy P, Bignon JD, et al. Effect of T-cell-epitope matching at HLA-DPB1 in recipients of unrelated-donor haemopoietic-cell transplantation: a retrospective study. Lancet Oncol (2012) 13(4):366-74. doi:10.1016/S1470-2045(12)70004-9

15. Pidala J, Lee SJ, Ahn KW, Spellman S, Wang HL, Aljurf M, et al. Nonpermissive HLA-DPB1 mismatch increases mortality after myeloablative unrelated allogeneic hematopoietic cell transplantation. Blood (2014) 124(16):2596-606. doi:10.1182/blood-2014-05-576041

\section{FUNDING}

This work was supported by grants from the Deutsche José Carreras Leukämie Stiftung (DJCLS R 15/02) to KF and PH, and the Dr. Werner Jackstädt Stiftung and the Joseph Senker Stiftung to $\mathrm{KF}$, and an Adaptive Biotechnologies Young Investigator Award to EA-B.

16. Brzostek J, Gascoigne NR. Thymic origins of T cell receptor alloreactivity Transplantation (2017) 101:1535-41. doi:10.1097/TP.0000000000001654

17. Rutten CE, van Luxemburg-Heijs SA, Halkes CJ, van Bergen CA, Marijt EW, Oudshoorn M, et al. Patient HLA-DP-specific CD4+ T cells from HLA-DPB1mismatched donor lymphocyte infusion can induce graft-versus-leukemia reactivity in the presence or absence of graft-versus-host disease. Biol Blood Marrow Transplant (2013) 19(1):40-8. doi:10.1016/j.bbmt.2012.07.020

18. Rutten CE, van Luxemburg-Heijs SA, van der Meijden ED, Griffioen M, Oudshoorn M, Willemze R, et al. HLA-DPB1 mismatching results in the generation of a full repertoire of HLA-DPB1-specific CD4+ T cell responses showing immunogenicity of all HLA-DPB1 alleles. Biol Blood Marrow Transplant (2010) 16(9):1282-92. doi:10.1016/j.bbmt.2010.03.018

19. Litjens NH, de Wit EA, Baan CC, Betjes MG. Activation-induced CD137 is a fast assay for identification and multi-parameter flow cytometric analysis of alloreactive T cells. Clin Exp Immunol (2013) 174(1):179-91. doi:10.1111/ cei. 12152

20. Robins HS, Campregher PV, Srivastava SK, Wacher A, Turtle CJ, Kahsai O, et al. Comprehensive assessment of T-cell receptor beta-chain diversity in alphabeta T cells. Blood (2009) 114(19):4099-107. doi:10.1182/blood-2009-04-217604

21. Carlson CS,Emerson RO, Sherwood AM, Desmarais C, ChungMW,Parsons JM, et al. Using synthetic templates to design an unbiased multiplex PCR assay. Nat Commun (2013) 4:2680. doi:10.1038/ncomms3680

22. Lefranc MP, Giudicelli V, Duroux P, Jabado-Michaloud J, Folch G, Aouinti S, et al. IMGT(R), the international ImMunoGeneTics information system(R) 25 years on. Nucleic Acids Res (2015) 43(Database issue):D413-22. doi:10.1093/ nar/gku1056

23. Pielou EC. Species-diversity and pattern-diversity in the study of ecological succession. J Theor Biol (1966) 10(2):370-83. doi:10.1016/0022-5193 (66) $90133-0$

24. Daley T, Smith AD. Predicting the molecular complexity of sequencing libraries. Nat Methods (2013) 10(4):325-7. doi:10.1038/nmeth.2375

25. DeWitt WS, Emerson RO, Lindau P, Vignali M, Snyder TM, Desmarais C, et al. Dynamics of the cytotoxic $\mathrm{T}$ cell response to a model of acute viral infection. J Virol (2015) 89(8):4517-26. doi:10.1128/JVI.03474-14

26. Morisita M. Measuring of the dispersion and analysis of distribution patterns. Mem Fac Sci Kyushu Univ Ser E Biol (1959) 2:215-35.

27. R_Core_Team. R: A Language and Environment for Statistical Computing. Vienna, Austria: R Foundation for Statistical Computing (2017). Available from: https://www.R-project.org/

28. RStudio_Team. RStudio: Integrated Development for R. Boston, MA: RStudio, Inc (2015). Available from: http://www.rstudio.com/

29. Emerson RO, Mathew JM, Konieczna IM, Robins HS, Leventhal JR. Defining the alloreactive $\mathrm{T}$ cell repertoire using high-throughput sequencing of mixed lymphocyte reaction culture. PLoS One (2014) 9(11):e111943. doi:10.1371/ journal.pone.0111943

30. Zuber J, Shonts B, Lau SP, Obradovic A, Fu J, Yang S, et al. Bidirectional intragraft alloreactivity drives the repopulation of human intestinal allografts and correlates with clinical outcome. Sci Immunol (2016) 1(4):eaah3732. doi:10.1126/sciimmunol.aah3732

31. Diaz G, Canas B, Vazquez J, Nombela C, Arroyo J. Characterization of natural peptide ligands from HLA-DP2: new insights into HLA-DP peptide-binding motifs. Immunogenetics (2005) 56(10):754-9. doi:10.1007/s00251-0040735-5

32. Arroyo J, Alvarez AM, Nombela C, Sanchez-Perez M. The role of HLA-DP beta residue 69 in the definition of antibody-binding epitopes. Hum Immunol (1995) 43(3):219-26. doi:10.1016/0198-8859(95)00022-V 
33. Diaz G, Catalfamo M, Coiras MT, Alvarez AM, Jaraquemada D, Nombela C, et al. HLA-DPbeta residue 69 plays a crucial role in allorecognition. Tissue Antigens (1998) 52(1):27-36. doi:10.1111/j.1399-0039.1998.tb03020.x

34. Diaz G, Amicosante M, Jaraquemada D, Butler RH, Guillen MV, Sanchez M, et al. Functional analysis of HLA-DP polymorphism: a crucial role for DPbeta residues $9,11,35,55,56,69$ and $84-87$ in T cell allorecognition and peptide binding. Int Immunol (2003) 15(5):565-76. doi:10.1093/intimm/ dxg057

35. Berretta F, Butler RH, Diaz G, Sanarico N, Arroyo J, Fraziano M, et al. Detailed analysis of the effects of Glu/Lys beta69 human leukocyte antigen-DP polymorphism on peptide-binding specificity. Tissue Antigens (2003) 62(6):459-71. doi:10.1046/j.1399-0039.2003.00131.x

36. Heemskerk MB, Roelen DL, Dankers MK, van Rood JJ, Claas FH, Doxiadis II, et al. Allogeneic MHC class I molecules with numerous sequence differences do not elicit a CTL response. Hum Immunol (2005) 66(9):969-76. doi:10.1016/j. humimm.2005.06.007

37. Heemskerk MB, Cornelissen JJ, Roelen DL, van Rood JJ, Claas FH, Doxiadis II, et al. Highly diverged MHC class I mismatches are acceptable for haematopoietic stem cell transplantation. Bone Marrow Transplant (2007) 40(3):193-200. doi:10.1038/sj.bmt.1705721

38. Weisdorf DJ. How closely related is graft-vs-leukemia to donor/recipient disparity? Best Pract Res Clin Haematol (2010) 23(4):525-8. doi:10.1016/j. beha.2010.09.015

39. Falkenburg JH, Jedema I. Allo-reactive T cells for the treatment of hematological malignancies. Mol Oncol (2015) 9(10):1894-903. doi:10.1016/j. molonc.2015.10.014

40. Fleischhauer K, Beelen DW. HLA mismatching as a strategy to reduce relapse after alternative donor transplantation. Semin Hematol (2016) 53(2):57-64. doi:10.1053/j.seminhematol.2016.01.010

41. Fleischhauer K, Zino E, Mazzi B, Sironi E, Servida P, Zappone E, et al. Peripheral blood stem cell allograft rejection mediated by CD4(+) T lymphocytes recognizing a single mismatch at HLA-DP beta $1^{\star} 0901$. Blood (2001) 98(4):1122-6. doi:10.1182/blood.V98.4.1122

42. Shaw BE, Marsh SG, Mayor NP, Russell NH, Madrigal JA. HLA-DPB1 matching status has significant implications for recipients of unrelated donor stem cell transplants. Blood (2006) 107(3):1220-6. doi:10.1182/blood-2005-08-3121

43. Shaw BE, Potter MN, Mayor NP, Pay AL, Smith C, Goldman JM, et al. The degree of matching at HLA-DPB1 predicts for acute graft-versus-host disease and disease relapse following haematopoietic stem cell transplantation. Bone Marrow Transplant (2003) 31(11):1001-8. doi:10.1038/sj.bmt.1704029

44. Corse E, Gottschalk RA, Allison JP. Strength of TCR-peptide/MHC interactions and in vivo T cell responses. J Immunol (2011) 186(9):5039-45. doi:10.4049/ jimmunol.1003650
45. van Panhuys N. TCR signal strength alters T-DC activation and interaction times and directs the outcome of differentiation. Front Immunol (2016) 7:6. doi:10.3389/fimmu.2016.00006

46. Hogquist KA. Signal strength in thymic selection and lineage commitment. Curr Opin Immunol (2001) 13(2):225-31. doi:10.1016/S0952-7915(00)00208-9

47. Crocchiolo R, Zino E, Vago L, Oneto R, Bruno B, Pollichieni S, et al. Nonpermissive HLA-DPB1 disparity is a significant independent risk factor for mortality after unrelated hematopoietic stem cell transplantation. Blood (2009) 114(7):1437-44. doi:10.1182/blood-2009-01-200378

48. PetersdorfEW,MalkkiM,O'HUiginC,Carrington M,GooleyT,HaagensonMD, et al. High HLA-DP expression and graft-versus-host disease. N Engl J Med (2015) 373(7):599-609. doi:10.1056/NEJMoa1500140

49. Fleischhauer K. Immunogenetics of HLA-DP - a new view of permissible mismatches. N Engl J Med (2015) 373(7):669-72. doi:10.1056/NEJMe1505539

50. Cherel M, Choufi B, Trauet J, Cracco P, Dessaint JP, Yakoub-Agha I, et al. Naive subset develops the most important alloreactive response among human CD4+ T lymphocytes in human leukocyte antigen-identical related setting. Eur J Haematol (2014) 92(6):491-6. doi:10.1111/ejh.12283

51. Distler E, Bloetz A, Albrecht J, Asdufan S, Hohberger A, Frey M, et al. Alloreactive and leukemia-reactive $\mathrm{T}$ cells are preferentially derived from naive precursors in healthy donors: implications for immunotherapy with memory T cells. Haematologica (2011) 96(7):1024-32. doi:10.3324/haematol. 2010.037481

52. Flomenberg N, Russo C, Ferrone S, Dupont B. HLA class I specific T lymphocyte clones with dual alloreactive functions. Immunogenetics (1984) 19(1):39-51. doi:10.1007/BF00364474

53. Strassman G, Bach FH. OKT4+ cytotoxic T cells can lyse targets via class I molecules and can be blocked by monoclonal antibody against T4 molecules. J Immunol (1984) 133(4):1705-9.

Conflict of Interest Statement: JR, MV, and EY have employment and equity ownership with Adaptive Biotechnologies. All other authors declare that the research was conducted in the absence of any commercial or financial relationships that could be construed as a potential conflict of interest.

Copyright (C) 2018 Arrieta-Bolaños, Crivello, Metzing, Meurer, Ahci, Rytlewski, Vignali, Yusko, van Balen, Horn, Falkenburg and Fleischhauer. This is an open-access article distributed under the terms of the Creative Commons Attribution License (CC $B Y$ ). The use, distribution or reproduction in other forums is permitted, provided the original author(s) and the copyright owner are credited and that the original publication in this journal is cited, in accordance with accepted academic practice. No use, distribution or reproduction is permitted which does not comply with these terms. 